\title{
Physically adjusted neutral detergent fiber system for lactating dairy cow rations. I: Deriving equations that identify factors that influence effectiveness of fiber
}

\author{
Robin R. White, ${ }^{*}$ Mary Beth Hall, $†$ Jeffrey L. Firkins, $\ddagger$ and Paul J. Kononoff $\S^{1}$ \\ *Department of Dairy Science, Virginia Tech, Blacksburg 24060 \\ †US Dairy Forage Research Center, USDA Agricultural Research Service, Madison, WI 53706 \\ fDepartment of Animal Sciences, The Ohio State University, Columbus 43210 \\ §Department of Animal Science, University of Nebraska-Lincoln, Lincoln, NE 68583-0908
}

\begin{abstract}
Physically effective neutral detergent fiber (peNDF) is the fraction of neutral detergent fiber (NDF) that stimulates chewing activity and contributes to the floating mat of large particles in the rumen. Multiplying dietary NDF by particle size has been used as an estimate of peNDF. In re-evaluating the concept of peNDF, we compared the use of peNDF as dietary $\mathrm{NDF} \times$ particle size with the use of individual NDF and particle size descriptors (physically adjusted NDF; paNDF) when used with other physical and chemical diet descriptors to predict dry matter (DM) intake (DMI), rumination time, and ruminal $\mathrm{pH}$ in lactating dairy cows. The purpose is to ultimately use these equations to estimate diet adequacy to maintain ruminal conditions. Each response variable had 8 models in a 2 (peNDF, paNDF) $\times 2$ (diet, diet and ruminal factors) $\times 2$ (DM, as fed basis) factorial arrangement. Particle size descriptors were those determined with the Penn State Particle Separator. Treatment means $(\mathrm{n}=241)$ from 60 publications were used in backward elimination multiple regression to derive models of response variables. When available, peNDF terms entered equations. Models containing peNDF terms had similar or lower unadjusted concordance correlation coefficients (an indicator of similar or lower accuracy and precision) than did models without peNDF terms. The peNDF models for rumen $\mathrm{pH}$ did not differ substantially from paNDF models. This suggests that peNDF can account for some variation in ruminal $\mathrm{pH}$; however, overt advantages of peNDF were not apparent. Significant variables that entered the models included estimated mean particle size; as fed or DM proportions retained on 19- and 8-mm sieves of the Penn State Particle Separa-
\end{abstract}

Received February 20, 2017.

Accepted May 28, 2017.

${ }^{1}$ Corresponding author: pkononoff $2 @ u n l . e d u$ tor; DMI; dietary concentrations of forage; forage NDF; CP; starch; NDF; rumen-degraded starch and rumendegraded NDF; and the interaction terms of starch $\times$ mean particle size, acid detergent fiber/NDF, and rumination time/DMI. Many dietary factors beyond particle size and NDF were identified as influencing the response variables. In conclusion, these results appear to justify the development of a modeling approach to integrate individual physical and chemical factors to predict effects on factors affecting rumen conditions.

Key words: chewing activity, effective fiber, particle size, ruminal $\mathrm{pH}$

\section{INTRODUCTION}

Dairy cattle are grass and roughage eaters (Hofmann, 1989) and consequently require coarse roughage to maintain normal rumen function and overall health (Cole and Mead, 1943). The positive relationship between particle size and chewing activity has long been proposed as part of a method for assessing the effect of coarse roughage in diets (Balch, 1971; Sudweeks et al., 1981; Nørgaard, 1989). Several investigators have sought to quantify coarseness of roughage so that these measures could be adopted into feeding recommendations (Santini et al., 1983; Mertens, 1997). At the 1995 American Dairy Science Association Annual Meeting, a symposium titled "Meeting the Fiber Requirements of Dairy Cows" was held, and companion papers from this symposium were published (Allen, 1997; Armentano and Pereira, 1997; Firkins, 1997; Mertens, 1997). These works collectively outline the need for fiber by dairy cattle.

The concept of physically effective NDF (peNDF) as a means for measuring the ruminal effects of coarse roughage was also introduced and was defined as the fraction of NDF that stimulates chewing activity and contributes to the floating mat of large particles in the rumen (Mertens, 1997). Mertens (1997) proposed 
that the peNDF of individual feedstuffs could be estimated by multiplying the NDF content of a feed by the proportion of material retained on a 1.18-mm sieve, though this approach assumes that NDF is uniformly distributed over all particles regardless of size. When updating the nutrient recommendations and after considering the merits of published mechanistic approaches, NRC (2001) chose not to include a peNDF system. The basis of this decision was a lack of studies available that validated and standardized any proposed methods and the lack of experimentally measured effectiveness coefficients among feeds. Instead, guidelines outlining minimum concentrations of NDF, forage NDF (fNDF), and maximum concentrations of NFC were published and have been used widely throughout the dairy industry (Table 4-3 in NRC, 2001).

Quantitative assessments of the physical characteristics of feed have been made using several different sieving methods (Murphy and Zhu, 1997). Historically, this most commonly has been done according to 1 of 2 methods. First, a Ro-Tap particle separator (W. S. Tyler, Mentor, $\mathrm{OH}$ ) equipped with a set of wire cloth sieves (ASABE, 2013) has been used for dry sieving and sometimes modified for wet sieving, especially of silages. Second, a mechanically driven forage particle separator device was engineered specifically to determine the particle size distribution of chopped forage (ASABE, 2017). Given the cost, weight, and size of the equipment and the need for electricity (or standardized water spray for wet sieving) to operate, these methods are not practical for on-farm evaluations of feed particle size (Maulfair and Heinrichs, 2012).

The Penn State Particle Separator (PSPS) is a portable and manually operated device that is widely used on farm to measure the particle size of both forages and TMR (Lammers et al., 1996; Heinrichs and Kononoff, 2002). Since its introduction in 1996, researchers have used it to evaluate the effects of TMR particle size on milk production, composition, chewing activities, and rumen fermentation. Zebeli et al. (2012) proposed a method for estimating peNDF by multiplying the sum of DM retained on 19- and 8-mm sieves of the PSPS by the NDF concentration of the diet and combining these measurements into a system that integrates chewing activity with ruminal $\mathrm{pH}$ and ruminal digestibilities of starch and NDF. Although this approach represents a major advancement in quantifying peNDF, several limitations in this system remain. First, sieving results are assumed to be equivalent whether expressed on an as-fed (AF) basis or a DM basis, and NDF is assumed to be distributed equally across particle sizes. These assumptions are not well supported by data because moisture affects particle size proportion; moisture has been reported to affect particle size measures and NDF concentration not uniformly distributed across sieves (Ranathunga et al., 2010). Second, the digestibility or fragility of forages has not been considered, although these factors are known to affect rumination times (Mertens, 1997). Third, few studies in the Zebeli et al. (2012) database had objectives of evaluating diets with large concentrations of nonforage fiber sources; several studies are now available that seek to replace both starch and forages with nonforage fiber sources (Bradford and Mullins, 2012). Fourth, wet (silage) and dry (hay) forages were not differentiated, although forage DM influences rumination activities (Beauchemin et al., 1997) and saliva production (Beauchemin et al., 2008). Fifth, in situ methods were used to determine rumen-degraded starch (dStarch), which may be poorly estimated in feeds containing either slowly or rapidly degradable starch (Offner and Sauvant, 2004), and rumen-degraded NDF (dNDF) was not considered; both have major effects on rumen fermentation and can be predicted from dietary nutrient composition (White et al., 2016). If these limitations are overcome, feeding recommendations for coarse particles and fiber could be standardized and included in a more robust system. For example, models might be made more accurate and responsive if they (1) recognize that dietary factors can affect eating and rumination times (Beauchemin, 1991), (2) consider eating and ruminating separately rather than combining these factors into total chewing time (sum of eating plus ruminating times), (3) use optimization routines that might be more appropriate than mathematical integration (Mayer et al., 1998), and (4) avoid the use of forced broken-line models because these may be too simplistic to describe a more complex, multifactorial system that is more dynamic over a variety of dietary conditions. Hence, the prior advances made with peNDF should first be challenged by comparing equations with peNDF (i.e., particle size multiplied by NDF) with similar equations in which peNDF is separated into its core components (i.e., particle size distinguished from NDF but potentially including other dietary nutrients).

The objective of this work was to re-evaluate the concept of peNDF by quantitatively summarizing the body of literature reporting physical and chemical characteristics of total diets and deriving equations that relate these to DMI, chewing behavior, and ruminal $\mathrm{pH}$. Data generated using the PSPS were used to enhance the potential for the system to be used in on-farm situations. We hypothesized that (1) particle size can be separated from the peNDF calculation and instead be included separately in a multiple regression that includes fNDF but also potentially other dietary composition factors; (2) dietary factors will improve accuracy and precision of predictions if total chewing is 
separated into eating and ruminating components, (3) chewing components will be better integrated to predict ruminal $\mathrm{pH}$ if particle distributions on sieves from the PSPS are calculated on a DM basis rather than on an AF basis; and (4) incorporating predicted rumen NDF or starch degradability estimates into models will improve fit compared with diet-only factors. To avoid confusion with nomenclature associated with previous systems and with the concept that future feeding recommendations for fiber should also account for particle size, we henceforth refer to a physically adjusted NDF (paNDF) system that aims to identify key factors that influence rumen fermentation. Thereby a paNDF system approach using individual factors is compared with peNDF in all equations.

\section{MATERIALS AND METHODS}

\section{Data Collection and Preparation}

Data were collected from published, peer-reviewed papers that reported particle size data using the PSPS on either an AF or DM basis in conjunction with rumen characteristics and chewing activity. Keywords used to search for relevant articles were "particle size," "chewing activity," "eating time," "ruminating time," and "rumen." Searches were conducted in the fall of 2016 using Google (http://www.scholar.google.com/) and PubMed (https://www.ncbi.nlm.nih.gov/pubmed) as well as the search function on the websites of Journal of Dairy Science (http://www.journalofdairyscience .org/), Canadian Journal of Animal Science (http:// www.nrcresearchpress.com/journal/cjas), Animal (https://www.cambridge.org/core/journals/animal), and Animal Feed Science and Technology (http://www .sciencedirect.com/science/journal/03778401). Every article recovered was screened for references with relevant titles for subsequent searches. If the title referred to animals other than lactating dairy cattle, the article was not considered. To make the results more readily applicable to the field, only studies that used the PSPS to measure feed particle size were included. A sieve measuring $4.0 \mathrm{~mm}$ is now available for the PSPS (Kmicikewycz et al., 2015; Kmicikewycz and Heinrichs, 2015); however, given the scarcity of published data using this sieve, it was not included in our study. Assuming a log-normal distribution, estimated mean particle size (MPS) was determined according to the calculations described by Waldo et al. (1971) using linear regression of the normal inverse of cumulative proportion of particles retained on 19-, 8-, and (when available) 1.18-mm sieves versus the logarithm (base 10) of screen size, solving for $y=0$. The standard deviation of MPS was calculated as the inverse of the slope. In total, 241 observations from 60 publications were used in the data set and are referenced in Supplemental Table S1 (https://doi.org/10.3168/jds.2017-12765). Data are summarized in Table 1.

Dietary composition described in the studies provided some of the inputs evaluated in the regressions, and dNDF and dStarch were estimated by equations described in White et al. (2016) because this information was rarely available from the studies. When specific chemical components of the diets were not reported, composition of individual feeds was assumed as the mean composition reported by the National Animal Nutrition Program (https://nanp-nrsp-9.org/), and the nutrient composition of the diet was calculated. Although it is good practice to adjust calculated nutrient composition of the TMR to better match reported dietary composition (White et al., 2017b), in this case it was not possible because dietary nutrient composition was missing. To minimize potential for introducing errors by calculating dietary composition, the distribution of diet chemical composition across the entire data set was compared before and after calculating missing chemical composition values to determine whether calculated values differed from measured values. The comparison of measured and calculated values is included in Table 2.

\section{Can peNDF Be Predicted by Multiplying Particle Size Data and Diet NDF?}

Two key issues in the prediction of peNDF are (1) accuracy of the NDF content of the particles and (2) whether particle size is described on a DM or AF basis. The most direct way to measure peNDF is to measure the NDF content of particles retained on a sieve 1.18 mm or greater (Mertens, 1997; Calberry et al., 2003; Grant et al., 2005); however, few researchers actually measure the NDF on sieved sample material, and most simply use the mean NDF content of the TMR. Although the limitation to this approach was described and prioritized for future study in the original peNDF approach (Mertens, 1997), only 7 studies in the current data set reported the NDF content of sample material (DM basis) on each sieve. Additionally, many studies reported PSPS particle size on either an AF or DM basis. Because of these issues, we used the 7 available studies (34 treatments) to evaluate whether the NDF content of individual sieve fractions differed from the NDF content of the total diet and whether differences in the NDF content of different sieve fractions could be accurately predicted. If they could not be well predicted, then inconsistencies would be deemed to justify subsequent comparison of alternative approaches to circumvent this limitation. First, from those 7 studies, we 
Table 1. Variables collected from peer-reviewed publications, included in the data set, and used in the meta-analysis

\begin{tabular}{|c|c|c|c|c|c|c|}
\hline Item & Variable & $\mathrm{n}$ & Mean & $\mathrm{SD}$ & Minimum & Maximum \\
\hline \multirow{8}{*}{ TMR particle size $^{1}$} & $19 \mathrm{~mm}(\% \mathrm{AF})$ & 110 & 11.7 & 10.2 & 0.3 & 46.6 \\
\hline & $19 \mathrm{~mm} \mathrm{NDF}$ (\% of DM) & 27 & 55.0 & 6.5 & 41.6 & 64.1 \\
\hline & $8 \mathrm{~mm}(\% \mathrm{AF})$ & 110 & 33.1 & 11.2 & 7.7 & 65.3 \\
\hline & $8 \mathrm{~mm} \mathrm{NDF}(\%$ of $\mathrm{DM})$ & 27 & 37.9 & 5.3 & 30.5 & 48.6 \\
\hline & $1.18 \mathrm{~mm}(\%$ of $\mathrm{DM})$ & 71 & 43.0 & 8.5 & 25.7 & 63.0 \\
\hline & MPS, AF basis ${ }^{2}$ (mm) & 110 & 6.6 & 2.9 & 1.3 & 16.6 \\
\hline & SDPS, DM basis ${ }^{3}(\mathrm{~mm})$ & 118 & 0.47 & 0.16 & 0.17 & 1.02 \\
\hline & SDPS, AF basis ${ }^{3}(\mathrm{~mm})$ & 110 & 0.44 & 0.20 & 0.19 & 1.85 \\
\hline \multirow[t]{3}{*}{ Chewing behavior } & Eating time $(\min / \mathrm{d})$ & 182 & 284 & 77.3 & 141 & 507 \\
\hline & Ruminating time $(\min / \mathrm{d})$ & 179 & 436 & 68.4 & 236 & 610 \\
\hline & Total chewing time $(\mathrm{min} / \mathrm{d})$ & 175 & 717 & 115 & 396 & 973 \\
\hline \multirow{4}{*}{ Forage characteristics } & Forage ( $\%$ of TMR DM) & 238 & 46.1 & 9.79 & 10.1 & 79.4 \\
\hline & Legume forage (\% of TMR DM) & 241 & 13.5 & 14.3 & 0.0 & 59.7 \\
\hline & Dry forage, hay ( $\%$ of TMR DM) & 241 & 10.3 & 13.1 & 0.0 & 59.5 \\
\hline & Wet forage, silage ( $\%$ of TMR DM) & 241 & 29.9 & 19.0 & 0.0 & 62.0 \\
\hline \multirow[t]{6}{*}{ Animal descriptions } & DMI $(\mathrm{kg} / \mathrm{d})$ & 224 & 22.7 & 3.3 & 14.7 & 31.6 \\
\hline & $\mathrm{BW}(\mathrm{kg})$ & 231 & 631 & 58.3 & 399 & 756 \\
\hline & DIM (d) & 240 & 116 & 54.0 & 17.0 & 292 \\
\hline & Milk yield (kg/d) & 197 & 34.1 & 7.4 & 14.2 & 51.3 \\
\hline & Milk fat (\%) & 196 & 3.43 & 0.46 & 2.27 & 4.91 \\
\hline & Milk protein (\%) & 192 & 3.14 & 2.55 & 2.20 & 3.76 \\
\hline
\end{tabular}

${ }^{1}$ As estimated on the TMR by the Penn State Particle Separator (Kononoff et al., 2003) and reported as a proportion of material retained on each $(19,8$, and $1.18 \mathrm{~mm})$ sieve on a DM or as-fed (AF) basis. When reported, NDF content of material retained on each sieve was also included. ${ }^{2}$ Mean particle size (MPS) estimated when material retained on each sieve of the Penn State Particle Separator was reported on either a DM basis or an as-fed (AF) basis.

${ }^{3}$ Standard deviation of mean particle size (SDPS) estimated when material retained on each sieve was reported on either a DM basis or an asfed (AF) basis.

used a mixed-effect ANOVA to test whether the NDF content of TMR material reported on each sieve differed from the NDF content of the diet. In this analysis (data not shown), sieve size affected $(P<0.001)$ the difference between diet NDF and NDF of material retained on each sieve. Additionally, least squares means indicated that the NDF content of material retained on sieves with diameters of $19 \mathrm{~mm}(P<0.001), 1.18$
$\mathrm{mm}(P=0.003)$, and the sum of $8+19 \mathrm{~mm}(\geq 8$ $\mathrm{mm} ; P=0.002)$ differed from the dietary NDF content (the weighted average of NDF on all sieves plus pan); however, the NDF content of material retained on the 8 -mm sieve was not different $(P=0.593)$ from dietary NDF percentage.

A second analysis was used to determine whether the NDF content of sieved fractions could be predicted

Table 2. Mean dietary composition (\% of DM) of diets used in studies and included in the meta-analysis, including both (1) as reported and (2) when not reported in the data set but supplemented with tabular values reported by the National Animal Nutrition Program (https://nanp-nrsp-9.org/)

\begin{tabular}{lccccccc}
\hline & \multicolumn{3}{c}{ As reported only } & & \multicolumn{3}{c}{ Reported and supplemented } \\
\cline { 2 - 3 } \cline { 6 - 7 } Item & $\mathrm{n}$ & Mean & $\mathrm{SD}$ & & $\mathrm{n}$ & Mean & $\mathrm{SD}$ \\
\hline $\mathrm{DM}(\%$ as fed $)$ & 230 & 56.6 & 9.6 & & 241 & 56.6 & 9.6 \\
$\mathrm{CP}$ & 241 & 16.9 & 1.5 & & 241 & 16.9 & 1.5 \\
$\mathrm{NDF}$ & 241 & 34.7 & 4.5 & & 241 & 34.7 & 4.6 \\
ADF & 198 & 20.9 & 3.4 & & 241 & 21.6 & 9.2 \\
Ash & 172 & 7.60 & 1.5 & & 241 & 6.98 & 2.3 \\
Starch & 157 & 26.0 & 6.2 & & 241 & 24.6 & 11.2 \\
Crude fat & 114 & 3.72 & 1.2 & & 241 & 3.72 & 2.9 \\
\hline
\end{tabular}


from dietary NDF, percentage of material on each sieve (on an AF or DM basis), or dietary chemical composition. A mixed-effect backward stepwise regression approach with study as a random effect was used to test how the response variables (NDF of material retained on each sieve) were affected by explanatory variables. Initial models included sieved results on a $\mathrm{DM}$ or $\mathrm{AF}$ basis, diet NDF percentage, and interaction between these 2 factors; diet ADF/NDF; proportion of forage in the diet; and fNDF (Table 3). Independent variables were sequentially eliminated if $P<0.10$. The corrected Akaike information criterion (Hurvich and Tsai, 1993) was evaluated at each step to ensure that it decreased with the removal of the variable. For each, the root mean squared error (RMSE; Bibby and Toutenburg, 1978) of the regression was divided by the observed standard deviation (SD) of the response variable to determine whether the modeled prediction of NDF on each sieve fraction had a predictive benefit compared with using a mean $\pm \mathrm{SD}$ from the data. Values for RMSE/SD $>1$ indicate that the model error was larger than the SD of the data, whereas values $<1$ indicate that the model error was lower than the data SD (i.e., improved compared with random variation). If sieve NDF could be predicted from diet NDF and sieve DM or $\mathrm{AF}$ percentages, we would expect that these variables (dietary NDF and sieve DM or AF percentages) and their interaction (diet NDF multiplied by sieve DM or AF percentage) would be the only significant variables included in the model because diet NDF multiplied by sieve DM or AF percentage (peNDF) should be approximately equal to sieve NDF percentage. Specific results of this analysis are discussed in detail in the Results and Discussion section; however, because of the lack of accurate predictions of values in this subset of data, subsequent models with the full data set were derived and compared for best fit without comparison with the ideal standard (i.e., NDF measured on each sieve). Models were based either on dietary NDF multiplied by $\mathrm{DM}$ or AF distributions of particles prior (i.e., peNDF; an interaction term, not a direct measurement) or on dietary NDF separate from percentage distributions of particles on sieves measured on a $\mathrm{DM}$ or $\mathrm{AF}$ basis as independent variables. We evaluated all possible comparisons of sieve fractions to be compared directly with peNDF calculated from only 1 sieve (e.g., dietary NDF multiplied by the percentage of particles retained on an 8-mm or greater sieve; Zebeli et al., 2012).

\section{Model Derivation Procedure for Prediction of DMI, Chewing Activities, and Ruminal $\mathrm{pH}$}

Models were derived using the lmer (Kuznetsova et al., 2015) package of $\mathrm{R}$ version 3.1.0 (R Core Team,

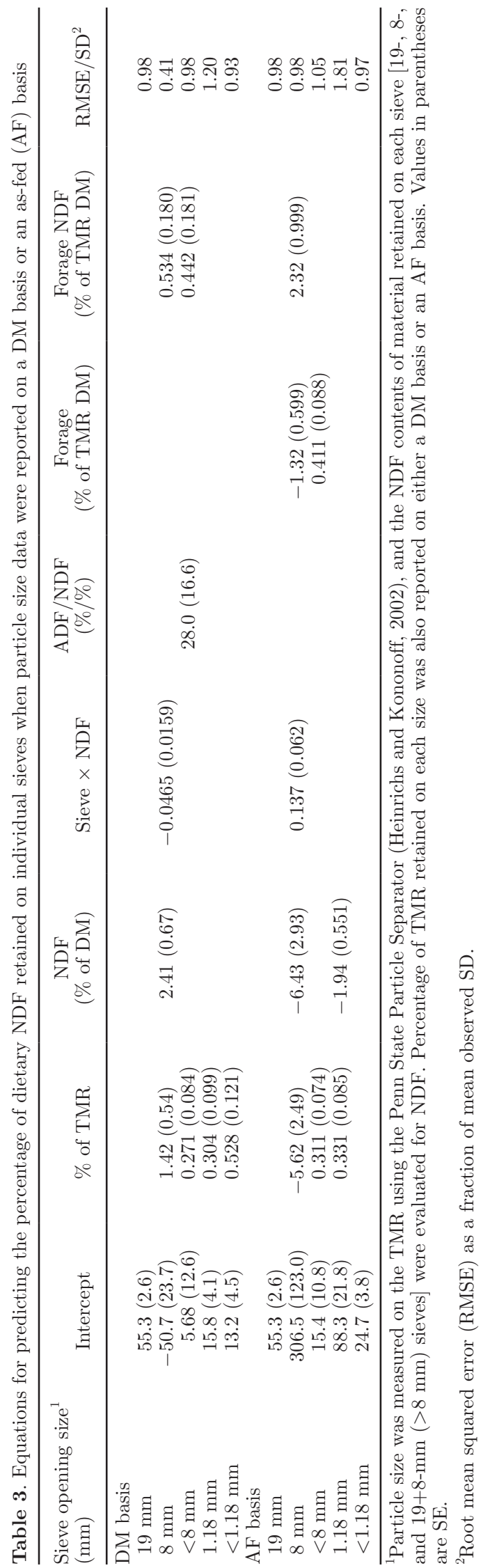

Journal of Dairy Science Vol. 100 No. 12, 2017 
2014). Models of 5 response variables were generated: DMI, eating time, ruminating time, total chewing activity (eating plus ruminating), and ruminal $\mathrm{pH}$. These response variables were selected to generate more robust representations of how diet physical and chemical form might affect rumen conditions. The correlations between variables used in models are listed in Supplemental Table S2 (https://doi.org/10.3168/jds.2017 -12765). For each response variable, 3 main factors were considered, and each possessed 2 alternatives, resulting in a $2 \times 2 \times 2$ factorial arrangement of 8 total models (Figure 1). Factor 1 represented peNDF as some measure of particle size multiplied by dietary NDF or else variables for sieve particle size measures represented separately from dietary NDF (individual factors). Factor 2 consisted of models with diet characteristics (Diet) or models that included diet characteristics plus rumen characteristics (Diet+Rumen). Factor 3 consisted of models that included particle size data expressed on an AF or DM basis. For each response variable, all reported equations are numbered 1 through 8 according to the layout in Figure 1, and starting variables associated with each equation are listed in Table 4. These models addressed several important issues, including (1) whether multiplying dietary NDF by the weight of material retained on sieves provides a useful input related to the response variable or whether these factors should be kept separate, (2) whether the inclusion of rumen factors - VFA, dNDF (White et al., 2016), and dStarch (White et al., 2016) - improves the association of particle size representations with ruminal $\mathrm{pH}$, and (3) whether the simpler expression of particle distributions on an AF basis can represent the more technically appropriate expression on a DM basis.

Weighted linear mixed-effects regression was used to derive models adapted from the procedure described in Roman-Garcia et al. (2016) and White et al. (2016). Continuous and class variables expected to affect the response variable were included as fixed effects. Study was included as a random effect. Regressions were weighted based on 1 /standard error of the mean (SEM). The SEM were sourced directly from studies; when not reported directly, SEM were calculated based on reported standard error of the difference or SD or were propagated assuming that errors were additive. Then, SEM were trimmed at one half of the mean SEM to protect against overweighting. If trimming at one half of the mean resulted in $>15 \%$ of observations being curtailed, SEM were trimmed instead at one fourth of the mean to prevent excessive adjustment resulting from weighting.

Initial models included all continuous and class variables that were considered a priori to potentially affect the response variable (Table 4). Models were reduced to include only significant variables by using a 4-phase backward stepwise elimination procedure. This backward elimination procedure has been used in several similar works and has successfully identified combinations of variables that explain significant variation in the response variable without excessive covariation or being overly sensitive to individual variable inclusion. Terms were sequentially eliminated from the model based on nonsignificance $(P>0.10$; phase 1$)$. Once a model was derived that contained only significant $(P \leq 0.05)$ variables or those with a tendency toward significance $(0.05<P \leq 0.10)$, the terms included in the initial model that were removed in the derivation process were sequentially tested in the final model to ensure that they were not appropriate for inclusion $(P$ $>0.10$; phase 2). During the backward elimination, variables with poorly defined $(P>0.10)$ linear effects were retained in the model if the corresponding quadratic or interaction term was significant $(P \leq 0.05)$. Once a model was derived that met the above criteria, variance inflation factors (VIF) were evaluated on all nonintercept variables (Akinwande et al., 2015). Terms correlated by calculation (squared and interaction terms) were allowed to have VIF $>10$; however, terms that were not correlated by calculation were removed if VIF was $>10$ (phase 3 ). Sieve measures were expected to be significantly related to one another. However, Grant (1997) observed the importance of coarse fiber to retain by-products, which thereby allowed interaction (i.e., justifying combinations) of sieve fractions. For this reason, final models were allowed to contain combinations of sieve fractions if VIF for these percentages was within the defined range. When models included multiple sieve fraction variables, removal of these variables was individually tested to determine the effect on significance of other factors and model fit (phase 4). If removal of the extraneous sieve fraction did not affect significance of other factors or model fit, the variable was removed to generate a more parsimonious model.

\section{Evaluating Model Performance}

Boerman et al. (2015) highlighted the concerns with using traditional model evaluation techniques on mixed-effect models-namely, least squares-based evaluations such as the RMSE are not always appropriate for models derived using log-likelihood approaches. As such, we evaluated models using the root estimated residual variance, $\hat{\sigma}_{e}$ (i.e., the estimated standard deviation for error), and the root estimated variance due to study, $\hat{\sigma}_{s}$ (i.e., the estimated standard deviation for study). Both statistics are reported in the same units as the dependent variable. To compare among models of the same response variable, concordance correlation 
coefficients (Lin, 1989) were calculated from predicted values that included the study adjustment (CCC) and values without the study adjustment (unadjusted; uCCC). These values assess both accuracy and precision of the models. The CCC values include the random intercept terms fit for each study and typically have more favorable fit statistics compared with the uCCC values, which evaluate the model at the mean value of the study effect. As described in White et al. (2017a,b,c), removing study effects from a mixed-model prediction is not a statistically accurate depiction of the model fit but rather is completed to give the reader an estimate of model fit in a naïve prediction scenario (where no study adjustment would be available before testing model performance). Because of this relevance to naïve prediction settings, we rely primarily on $\mathrm{uCCC}$ for evaluating model precision and accuracy. Because the resulting models differed considerably in the number of observations used in derivation, comparison of models based on CCC or uCCC was restricted to those model combinations that were derived from similar numbers of treatments because it is difficult to draw conclusions

Factor I. Independent variables; including individual factors or physically effective NDF (peNDF) representations of effective fiber and

Factor II. Independent

Factor III. Independent variables; TMR particle size data, dry matter (DM) or as fed (AF) basis

the physically adjusted (paNDF) system testing individual factors
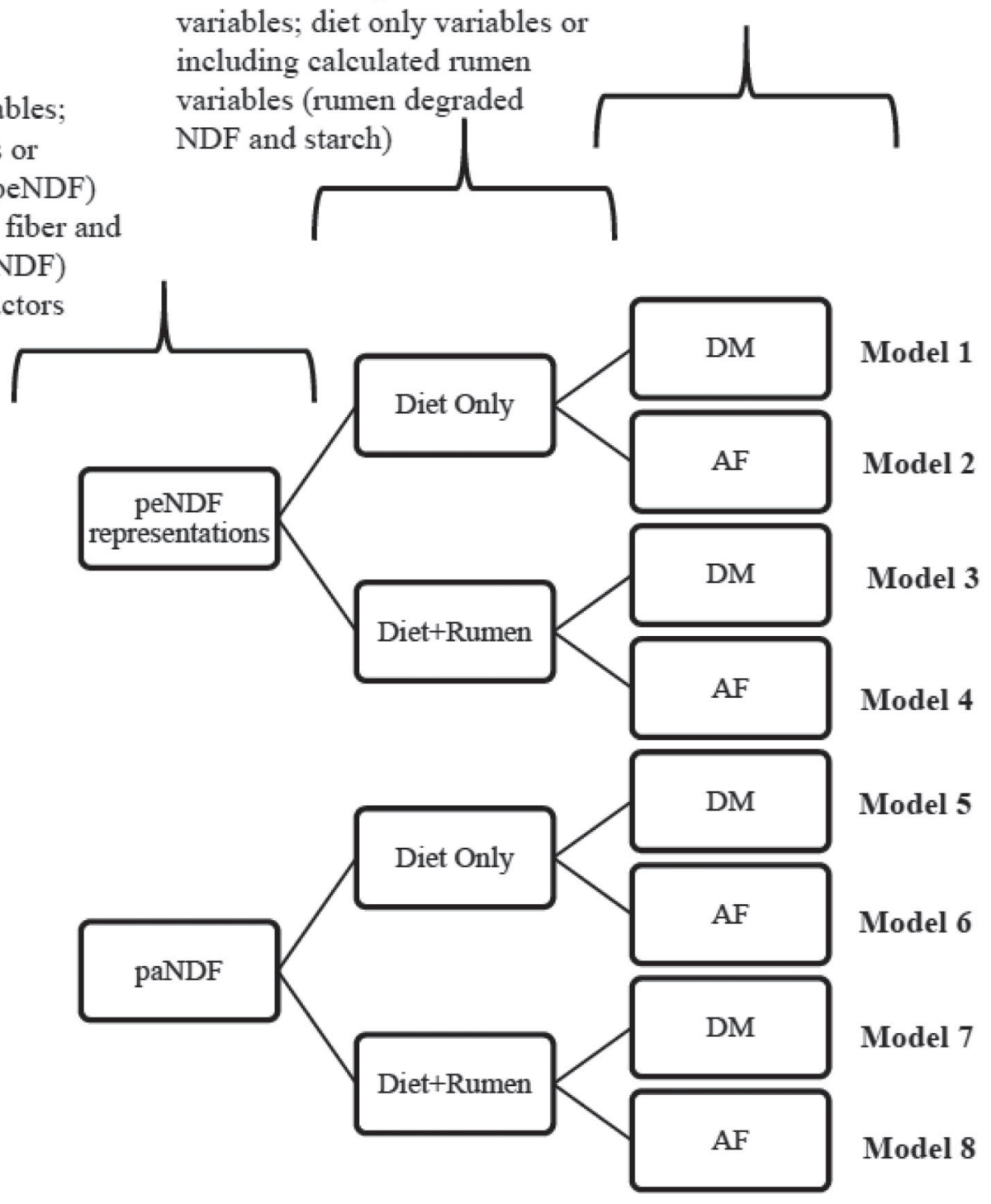

Figure 1. Depiction of the permutation of models that were developed to evaluate 3 main factors each possessing 2 combinations, resulting in a $2 \times 2 \times 2$ factorial arrangement of models. 
Table 4. Variable combinations used in initial models (1-8; see Figure 1 for model descriptions) before subjecting to stepwise backward elimination ${ }^{1}$

\begin{tabular}{|c|c|c|c|c|c|c|c|c|}
\hline \multirow[b]{2}{*}{ Item $^{2}$} & \multicolumn{8}{|c|}{ Model no. } \\
\hline & 1 & 2 & 3 & 4 & 5 & 6 & 7 & 8 \\
\hline $19 \mathrm{~mm}(\% \text { of } \mathrm{DM})^{3}$ & $\mathrm{x}$ & & $\mathrm{x}$ & & $\mathrm{x}$ & & $\mathrm{x}$ & \\
\hline $19 \mathrm{~mm}(\% \text { of } \mathrm{DM})^{3} \times \operatorname{diet} \mathrm{NDF}(\%$ of $\mathrm{DM})$ & $\mathrm{x}$ & & $\mathrm{x}$ & & & & & \\
\hline $19 \mathrm{~mm}(\% \text { of } \mathrm{AF})^{3}$ & & $\mathrm{x}$ & & $\mathrm{x}$ & & $\mathrm{x}$ & & $\mathrm{x}$ \\
\hline $19 \mathrm{~mm}(\% \text { of } \mathrm{AF})^{3} \times \operatorname{diet} \mathrm{NDF}(\%$ of $\mathrm{DM})$ & & $\mathrm{x}$ & & $\mathrm{x}$ & & & & \\
\hline $8 \mathrm{~mm}(\% \text { of } \mathrm{DM})^{3}$ & $\mathrm{x}$ & & $\mathrm{x}$ & & $\mathrm{x}$ & & $\mathrm{x}$ & \\
\hline $8 \mathrm{~mm}(\% \text { of } \mathrm{DM})^{3} \times \operatorname{diet} \mathrm{NDF}(\%$ of $\mathrm{DM})$ & $\mathrm{x}$ & & $\mathrm{x}$ & & & & & \\
\hline $8 \mathrm{~mm}(\% \text { of } \mathrm{AF})^{3}$ & & $\mathrm{x}$ & & $\mathrm{x}$ & & $\mathrm{x}$ & & $\mathrm{x}$ \\
\hline $8 \mathrm{~mm}(\% \text { of } \mathrm{AF})^{3} \times \operatorname{diet} \mathrm{NDF}(\%$ of $\mathrm{DM})$ & & $\mathrm{x}$ & & $\mathrm{x}$ & & & & \\
\hline$>8 \mathrm{~mm}(\% \text { of } \mathrm{DM})^{3}$ & $\mathrm{x}$ & & $\mathrm{x}$ & & $\mathrm{x}$ & & $\mathrm{x}$ & \\
\hline$>8 \mathrm{~mm}(\% \text { of DM) })^{3} \times \operatorname{diet} \mathrm{NDF}(\%$ of $\mathrm{DM})$ & $\mathrm{x}$ & & $\mathrm{x}$ & & & & & \\
\hline$>8 \mathrm{~mm}(\% \text { of } \mathrm{AF})^{3}$ & & $\mathrm{x}$ & & $\mathrm{x}$ & & $\mathrm{x}$ & & $\mathrm{x}$ \\
\hline$>8 \mathrm{~mm}(\% \text { of } \mathrm{AF})^{3} \times \operatorname{diet} \mathrm{NDF}(\%$ of $\mathrm{DM})$ & & $\mathrm{x}$ & & $\mathrm{x}$ & & & & \\
\hline TMR MPS, DM basis (mm) & $\mathrm{x}$ & & $\mathrm{x}$ & & $\mathrm{x}$ & & $\mathrm{x}$ & \\
\hline TMR MPS, DM basis $(\mathrm{mm}) \times \operatorname{diet} \operatorname{NDF}(\%$ of DM) & $\mathrm{x}$ & & $\mathrm{x}$ & & & & & \\
\hline TMR MPS, AF basis (mm) & & $\mathrm{x}$ & & $\mathrm{x}$ & & $\mathrm{x}$ & & $\mathrm{x}$ \\
\hline TMR MPS, AF basis $(\mathrm{mm}) \times \operatorname{diet}$ NDF $(\%$ of DM) & & $\mathrm{x}$ & & $\mathrm{x}$ & & & & \\
\hline TMR SDPS, DM basis (mm) & $\mathrm{x}$ & & $\mathrm{x}$ & & $\mathrm{x}$ & & $\mathrm{x}$ & \\
\hline TMR SDPS, AF basis (mm) & & $\mathrm{x}$ & & $\mathrm{x}$ & & $\mathrm{x}$ & & $\mathrm{x}$ \\
\hline Eating time $(\mathrm{min} / \mathrm{d})$ & & & $\mathrm{x}$ & $\mathrm{x}$ & & & $\mathrm{x}$ & $\mathrm{x}$ \\
\hline Eating time/DMI (min/kg) & & & $\mathrm{x}$ & $\mathrm{x}$ & & & $\mathrm{x}$ & $\mathrm{x}$ \\
\hline Ruminating time $(\min / \mathrm{d})$ & & & $\mathrm{x}$ & $\mathrm{x}$ & & & $\mathrm{x}$ & $\mathrm{x}$ \\
\hline Ruminating time/DMI ( $\mathrm{min} / \mathrm{kg}$ ) & & & $\mathrm{x}$ & $\mathrm{x}$ & & & $\mathrm{x}$ & $\mathrm{x}$ \\
\hline Total chewing time $(\mathrm{min} / \mathrm{d})$ & & & $\mathrm{x}$ & $\mathrm{x}$ & & & $\mathrm{x}$ & $\mathrm{x}$ \\
\hline Total chewing time/DMI ( $\mathrm{min} / \mathrm{kg})$ & & & $\mathrm{x}$ & $\mathrm{x}$ & & & $\mathrm{x}$ & $\mathrm{x}$ \\
\hline $\mathrm{pH}$ & & & $\mathrm{x}$ & $\mathrm{x}$ & & & $\mathrm{x}$ & $\mathrm{x}$ \\
\hline Acetate $(\mathrm{mol} / 100 \mathrm{~mol})$ & & & $\mathrm{x}$ & $\mathrm{x}$ & & & $\mathrm{x}$ & $\mathrm{x}$ \\
\hline Propionate (mol/100 mol) & & & $\mathrm{x}$ & $\mathrm{x}$ & & & $\mathrm{x}$ & $\mathrm{x}$ \\
\hline Butyrate $(\mathrm{mol} / 100 \mathrm{~mol})$ & & & $\mathrm{x}$ & $\mathrm{x}$ & & & $\mathrm{x}$ & $\mathrm{x}$ \\
\hline $\mathrm{dNDF}^{4}(\%$ of NDF$)$ & & & $\mathrm{x}$ & $\mathrm{x}$ & & & $\mathrm{x}$ & $\mathrm{x}$ \\
\hline Starch degradability ${ }^{4}$ ( $\%$ of starch) & & & $\mathrm{x}$ & $\mathrm{x}$ & & & $\mathrm{x}$ & $\mathrm{x}$ \\
\hline
\end{tabular}

${ }^{1}$ All models also included effects for BW, $\mathrm{kg}$; DMI, $\mathrm{kg} / \mathrm{d}$; DMI squared, (kg/d) ${ }^{2}$; ADF to NDF ratio, \%/\%; and as percentages of TMR DM: diet forage, $\%$; forage NDF, $\%$; forage NDF squared, $\%^{2}$; dry forage (hay), $\%$; wet forage (silage), $\%$; NDF, $\%$; NDF squared, $\%^{2}$; starch, $\%$; starch squared, $\%^{2}$; FA, $\%$; FA squared, $\%^{2}$. ${ }^{2} \mathrm{MPS}=$ estimated mean particle size from Penn State Particle Separator data; SDPS = standard deviation of the mean particle size.

${ }^{3}$ As estimated on the TMR using the Penn State Particle Separator (Heinrichs and Kononoff, 2002) and reported as proportion of material retained on each $(19,8$, and $1.18 \mathrm{~mm}$ ) sieve on a DM or as-fed (AF) basis.

${ }^{4}$ Predicted rumen-degraded NDF (dNDF) and starch degradability were estimated from dietary ingredients and chemical composition by White et al. (2016) and were not used in predictions of DMI.

about the fit of models derived from data sets that differ greatly in number of observations. Residual versus predicted value plots for each of the equations are presented in Supplemental Figures S1 through S40 (https://doi.org/10.3168/jds.2017-12765). It is important to note that the objective of this study was not to develop a model that would definitively predict ruminal $\mathrm{pH}$ or chewing behavior but rather to better understand how dietary physical and chemical form affects these responses so that they could be used to guide ration formulation and evaluation. As such, comparison among models was useful but not the primary goal of the exercise. In a companion paper (White et al., 2017a), these models are evaluated for suitability in an equation system designed to define dietary physical and chemical form recommendations.

\section{RESULTS AND DISCUSSION}

\section{Data Description}

Table 1 summarizes the descriptive statistics of the data. The number of observations across variables is not consistent but is reflective of what was reported from each published study. Table 2 lists the mean dietary composition (\% of DM) of diets used in studies and included in the meta-analysis, including both (1) as reported and (2) when not reported in the data set but supplemented with tabular values reported by the National Animal Nutrition Program (https:// nanp-nrsp-9.org/). Both diet composition and particle size are generally reflective of data from other metaanalyses (Nousiainen et al., 2009; Roman-Garcia et al., 
2016) and survey-based studies (Lammers et al., 1996; Heinrichs et al., 1999; Sova et al., 2014).

\section{Measuring peNDF: Particle Size Data Expressed on an AF or DM Basis Multiplied by Dietary NDF}

Particles are reduced in size during eating, when saliva is added to form a bolus to be swallowed. However, most of the comminution occurs when particles are ruminated; only minor reduction in size occurs after passage (Nørgaard, 2006). The resistance to the flow of particles out of the rumen is in part governed by the size of the particles. For example, in sheep, only a very small proportion of particles (i.e., 1-3\%) greater than $1.18 \mathrm{~mm}$ passed out of the reticulorumen (Poppi et al., 1980). This observation has given rise to the critical size theory, which suggests that most feed particles must be reduced to a particle size of less than $1.18 \mathrm{~mm}$ to pass out of the rumen for further digestion. This size threshold in lactating dairy cattle has been suggested to be greater than $1.18 \mathrm{~mm}$ and may be as large as between 3.0 and $5.0 \mathrm{~mm}$ (Cardoza, 1985; Shaver et al., 1988; Maulfair et al., 2011). This difference is likely to be a result of differences in body size, feed consumption, behaviors related to muzzle size, and perhaps even tactile abilities of the tongue and mouth. Nonetheless, Mertens (1997) proposed multiplying the NDF content of a feed by the proportion of material retained on a $1.18-\mathrm{mm}$ sieve as a potentially useful measure of peNDF that stimulates chewing activity and contributes to the floating mat of large particles in the rumen. Given the increased use of the PSPS on commercial farms, 19 and $8 \mathrm{~mm}$ have been proposed to replace use of the 1.18-mm sieve when measuring peNDF (Zebeli et al., 2008a, 2010, 2012; Nasrollahi et al., 2015, 2016). A key assumption to this approach is that particle size results achieved through sieving are equivalent when expressed on an $\mathrm{AF}$ or DM basis and, furthermore, that NDF is distributed equally across particle sizes. In contrast to these assumptions, moisture affects particle size measures because the fractions retained differ in DM, and NDF is not uniformly distributed across sieves (Ranathunga et al., 2010). Therefore, we explored whether the NDF content of TMR particles retained on each sieve of the PSPS could be determined from the mean NDF content of a TMR and from particle size data expressed on an AF or DM basis. In comparison with the mean NDF content of the TMR, material retained on all but the $8-\mathrm{mm}$ sieve was significantly different among the $\mathrm{AF}$ versus DM models (data not shown).

Although typically used as metrics of effective fiber, neither model of DM or AF material on a sieve multiplied by diet NDF was an ideal approach to predicting the NDF content of the sieved material. Frequently, other descriptors of diet (e.g., proportion of forage in the TMR, NDF percentage, ADF/NDF, or fNDF) were also significant predictors (Table 3). Practically, the significance of these variables suggests that, despite an assumption to estimate peNDF (Mertens, 1997), the NDF content of material on a sieve is not always equal to dietary NDF, is affected by the method of reporting particle size data, and is inconsistently related to other dietary factors. This finding is not surprising. Kononoff et al. (2003) identified that particle size of corn silage, estimated on a DM basis, gave a greater percentage of particles that passed through the 8-mm sieve compared with particle distribution on an AF basis. Additionally, conventional and kernel-processed silages generate different distributions of AF or DM material on the 19- and 8-mm sieves, and NDF as a percentage of DM was twice as high on the 19- and 8-mm sieves as in the collection pan (Weiss and Wyatt, 2000). These inconsistencies are not isolated to corn silage. Jaster and Murphy (1983) identified that chopping alfalfa hay created stems with greater concentrations of NDF and finer particles with lower concentrations of NDF. Based on this previous work and the quantitative summary conducted herein, we conclude that it is incorrect to assume that expressing particle size on an AF basis is equivalent to a DM basis. The NDF content of a TMR sample does not uniformly represent the NDF content of different particle size fractions. In reality, use of dietary NDF multiplied by any particle size fraction invokes an interaction term for dietary descriptors rather than any actual single quality of the diet. Accordingly, when calculating peNDF, the NDF content should be that determined on individual sieve fractions, which was suggested by Mertens (1997). Acknowledging that calculation of peNDF has potential limitations, we maintained the peNDF product as it is presently used (particle size by dietary NDF) for comparison with paNDF and for potential direct benefit for predicting biological responses (i.e., eating time, ruminating time, total chewing activity, ruminal $\mathrm{pH}$ in animals); comparative models are listed in Table 4.

\section{Models of DMI, Chewing Activities, and Ruminal pH}

Before introducing each model, it is important to re-emphasize that our intent was not to present models that simply predict DMI, chewing activities, and ruminal $\mathrm{pH}$. By summarizing the observed responses found in the published literature we were able to study the interrelations between the chemical and physical relationships of the diet and attempt to quantify their associations with rumen conditions (namely $\mathrm{pH}$ ).

Prediction of DMI. The prediction of DMI is challenging because it is affected by many factors, includ- 
ing production, stage of lactation, diet composition, environment (Holter et al., 1997), and genetic influence (Vallimont et al., 2010). Therefore, we note that more exhaustive models are needed to robustly predict DMI under a variety of conditions, but DMI was modeled for incorporation into a paNDF system (White et al., 2017a) because peNDF reached a threshold above which DMI was progressively limited by gut fill (Zebeli et al., 2012). The number of observations used in model derivation differed by model (67-80; Table 5). For those models with similar numbers of observations used, models based on AF particle size distributions appeared to have a slight advantage over those based on DM particle distributions (uCCC: $0.84-0.86$ vs. 0.77-0.82; Table 5). When dNDF and dStarch were included in the initial rumen variable models, as expected and observed by others (Oba and Allen, 1999), dNDF was consistently a significant effector of DMI. Inclusion of rumen variables moderately improved fit of models based on AF particle distributions (uCCC Equation 4 $=0.88$ vs. Equation $2=0.84$ and Equation $8=0.98$ vs. Equation $6=0.86$; Table 5 ) but not in models based on DM particle distributions (uCCC Equation $3=0.77$ vs. Equation $1=0.81$ and Equation $7=0.76$ vs. Equation $5=0.82$; Table 5$)$. The model with the second highest uCCC of any model compared (Equation $4=0.88$; Table 5) contained no metrics of particle size or NDF of sieved fractions and only included terms for dry (hay) and wet forage (silage) percentage, $\mathrm{CP}, \mathrm{NDF}, \mathrm{ADF} /$ $\mathrm{NDF}$, and dNDF. Models with peNDF (sieve $\times$ diet NDF) representations and rumen variables had reduced accuracy and precision compared with paNDF system models containing individual factors only (uCCC Equation $4=0.88$ vs. Equation $8=0.98$; Table 5 ).

Prediction of Eating Time. The physical act of eating involves the prehension of feed by the mouth, which is followed by chewing and then swallowing of the boli (Beauchemin, 1991). Major factors known to affect eating activity include the proportion of forage and the chemical composition and physical processing of the diet (Albright, 1993; Susenbeth et al., 1998). Final models of eating time are included in Table 6 . There were small and inconsistent differences in fit statistics among the DM and AF models. In the case of peNDF representations without rumen variables, fit statistics of the DM models were not substantially different than the AF models ( $\mathrm{uCCC}$ Equation $1=0.80$ vs. Equation $2=0.79$; Table 6 ). For the peNDF models with rumen digestibility representations and the models with the paNDF system, the AF models have a slight advantage in terms of fit (uCCC Equation $4=0.78$ vs. Equation $5=0.71$ to Equation $3=0.75$; Table 6 ). Because the AF models were based on a lower number of observations compared with the DM models ( $\mathrm{n}=48$ vs. 65 ), this difference in fit may be attributable to a smaller and more consistent data set. Rumen measures did not affect $(P>0.10)$ eating time; however, inclusion of rumen measures in the model generated different patterns of dietary variables that were removed during the backward elimination and therefore returned different final models. The lack of significance of rumen dNDF and dStarch was somewhat surprising because Jensen et al. (2016) noted that energy intake affected eating activity.

For peNDF models based on DM, particle distributions also included material retained on the $19-\mathrm{mm}$ sieve multiplied by NDF of sieve fraction $(19 \mathrm{~mm} \times \mathrm{NDF})$ as a significant term. For models based on AF particle distributions and including rumen factors, the interaction of MPS with NDF (MPS $\times$ NDF) was significant. Model fit was marginally improved for the models that included peNDF representations compared with individual factor models that separated particle size from NDF (uCCC Equation $1=0.80$ vs. Equation $5=0.71$; Equation $2=0.79$ vs. Equation $6=0.78$; Equation 3 $=0.75$ vs. Equation $7=0.70$; and Equation $4=0.78$ vs. Equation $8=0.78$; Table 6 ). The significance of these factors in the peNDF models and the difference in model fit statistics suggest that representing peNDF as the product of dietary NDF content and DM or AF particle distribution may represent biological factors for regulating eating time.

As particle size increases, eating time also increases because of the physical act of chewing as well as foraging behavior (Leonardi et al., 2005; Devries et al., 2008; Zebeli et al., 2008b; Maulfair et al., 2010, 2011); however, this relationship has not always been observed (Yang, 2007). Nonetheless, Beauchemin et al. (2008) reported that cows consume concentrate 3 to 12 times faster than forages but produce less saliva per unit of chewing activity. A general concept related to peNDF is that the act of chewing, whether it be eating or ruminating, stimulates saliva production, and this saliva acts to buffer the ruminal $\mathrm{pH}$. Thus, increasing eating activity may exert influence on increasing ruminal $\mathrm{pH}$; however, saliva is also produced during resting even though the rate of secretion is 1.3 to 2 times slower than during eating (Maekawa et al., 2002a,b).

\section{Prediction of Rumination Time}

The act of ruminating has been described by Beauchemin (1991) as a cyclical process characterized by regurgitation of ingesta, remastication, and reswallowing. Upon reaching the mouth, a small portion of liquid and small particles contained in the bolus are reswallowed, whereas the remaining bolus material is remasticated and mixed with saliva for 30 to $60 \mathrm{~s}$ before it is reswallowed. In general, rumination is associated 
with a quiet and relaxed state of awareness and is often exhibited when animals are lying down with their heads and eyelids lowered (Albright and Arave, 1997). Physiologically, the act of ruminating is also closely integrated with reticuloruminal motility and, consequently, overall gut health (Van Soest, 1994). Final models of rumination time are included in Table 7 . Models based on AF particle distributions consistently had marginally greater uCCC compared with models based on DM particle distributions (uCCC Equation $8=0.82$ to Equation $4=0.85$ vs. Equations $1,5=0.63$ to Equations 3, $7=0.64$; Table 7 ); however, this difference in fit statistics may result from differences in the size and consistency of the data sets. Models of DM particle distributions included multiple particle size variables; however, models of AF particle distributions typically included less than 2 variables for particle size. Particle size data reported on a DM basis could lead to more specific information on the diet's effect on rumination activities; however, the lack of a corresponding improvement in fit statistics precludes us from confidently concluding the superiority of a DM basis.

Models of rumination time with peNDF representations did not differ substantially from individual factor models in terms of fit (uCCC Equation $1=0.63$ to Equation $4=0.85$ vs. Equation $5=0.63$ to Equation $6=0.84$; Table 7 ). The parameter estimates for peNDF representations were significant only in models

Table 5. Parameter estimates in models of DMI when TMR particle size measure was (physically effective NDF; peNDF) or was not (physically adjusted NDF; paNDF) multiplied by diet NDF and including diet variables without (Diet) or with (Diet+Rumen) rumen digestibility when TMR sieved material was reported on an as-fed (AF) or DM basis ${ }^{1}$

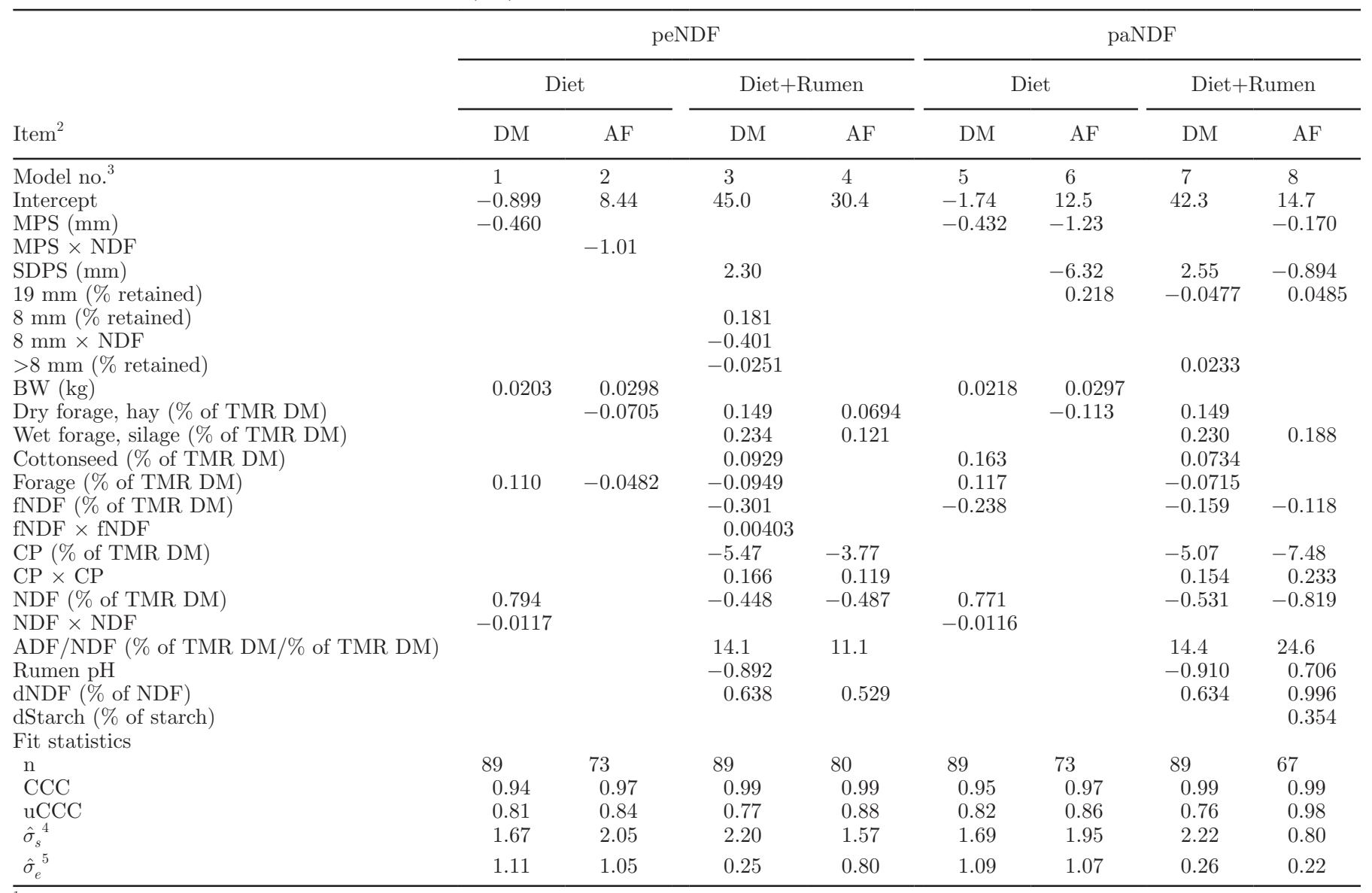

${ }^{1}$ Particle size was measured on the TMR by the Penn State Particle Separator (Heinrichs and Kononoff, 2002) and reported as \% of TMR retained on the 19-, 8-, and 19+8-mm (>8 $\mathrm{mm})$ sieves on a DM basis or an AF basis.

${ }^{2}$ All coefficients are $P \leq 0.05$. Units of individual terms in interactions are the same as for the single terms. MPS $=$ mean particle size estimated when material retained in each sieve of the Penn State Particle Separator was reported on either a DM basis or an AF basis; SDPS = standard deviation of the mean particle size; fNDF = forage NDF; dNDF = rumen-degraded NDF as estimated by White et al. (2016); dStarch = rumendegraded starch as estimated by White et al. (2016); CCC = concordance correlation coefficient; uCCC = unadjusted CCC.

${ }^{3}$ Model number refers to those listed in Figure 1 and Table 4.

${ }^{4}$ Square root of the estimated variance associated with study.

${ }^{5}$ Square root of the estimated variance associated with residual error. 
based on AF particle distributions and only when NDF multiplied by proportion of material retained on the 8-mm sieve (AF basis) was used. The lack of difference in model fit between the different scenarios of peNDF representation and models including individual factors suggests that the proportion of rumination behavior explained using peNDF can also be explained more directly by the percentage of material on the 8- and $19-\mathrm{mm}$ sieves and the NDF content of the diet. By nature of its determination, peNDF does not allow us to determine the nature of particle size and NDF content individually, and the representation might not account for the distribution of particle size.

Rumen-degraded NDF and dStarch were significant in both DM- and AF-based models and were inversely related to rumination activity; however, minimal differences in fit statistics were observed (Equation $5=$ 0.63 and Equation $6=0.84$ vs. Equation $7=0.64$ and
Equation $9=0.82$ to Equation $4=0.85$; Table 7 ). Models based on DM particle distributions contained significant effects for dNDF and dStarch, but models based on AF particle distributions included significant coefficients for dStarch but not dNDF. The effect of rumen digestibility on rumination activity is rarely studied in specific and controlled conditions, but rumen fermentation likely reduces plant tissue strength and increases fragility, thereby reducing the need for the particle size to be reduced through rumination (Allen and Mertens, 1988; Schadt et al., 2012). Consequently, these rumen factors tended to displace variables describing feedstuff inclusion (wet forage percentage and cottonseed percentage) and $\mathrm{ADF} / \mathrm{NDF}$, all of which are factors likely related to tissue strength and fragility (Grant, 2010).

Prediction of Total Chewing Time. Final models of total chewing time are included in Table 8. Models

Table 6. Parameter estimates in models of eating time when TMR particle size measure was (physically effective NDF; peNDF) or was not (physically adjusted NDF; paNDF) multiplied by diet NDF and including diet variables without (Diet) or with (Diet+Rumen) rumen digestibility when TMR sieved material was reported on an as-fed (AF) or DM basis ${ }^{1}$

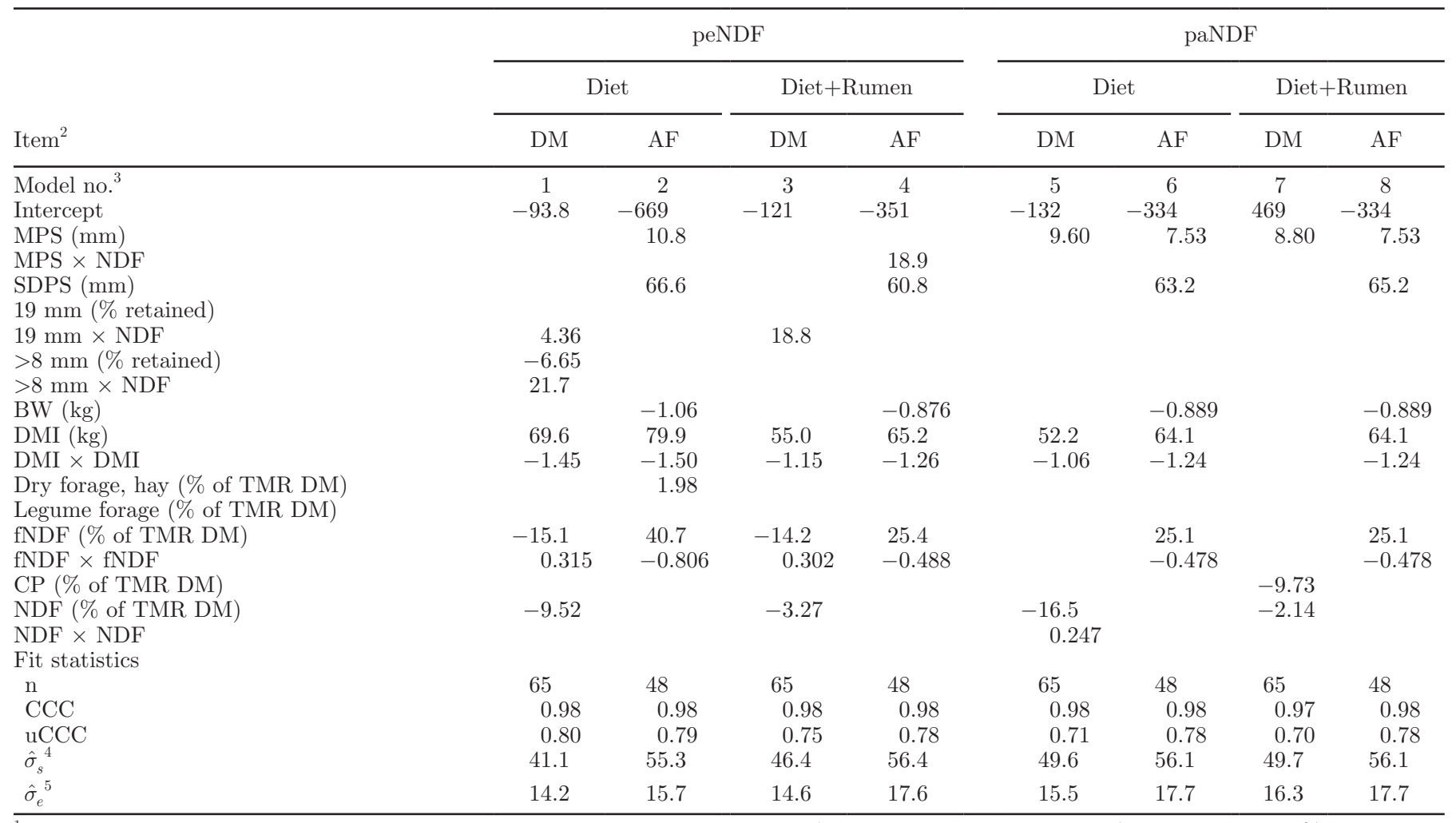

${ }^{1}$ Particle size was measured on the TMR by the Penn State Particle Separator (Heinrichs and Kononoff, 2002) and reported as \% of TMR retained on the 19-, 8-, and 19+8-mm (>8 $\mathrm{mm})$ sieves on a DM basis or an AF basis.

${ }^{2}$ All coefficients are $P \leq 0.05$. Units of individual terms in interactions are the same as for the single terms. MPS $=$ mean particle size estimated when material retained in each sieve of the Penn State Particle Separator was reported on either a DM basis or an AF basis; SDPS = standard deviation of the mean particle size; $\mathrm{fNDF}=$ forage $\mathrm{NDF} ; \mathrm{CCC}=$ concordance correlation coefficient; $\mathrm{uCCC}=$ unadjusted $\mathrm{CCC}$.

${ }^{3}$ Model number refers to those listed in Figure 1 and Table 4.

${ }^{4}$ Square root of the estimated variance associated with study.

${ }^{5}$ Square root of the estimated variance associated with residual error. 
Table 7. Parameter estimates in models of ruminating time when TMR particle size measure was (physically effective NDF; peNDF) or was not (physically adjusted NDF; paNDF) multiplied by diet NDF and including diet variables without (Diet) or with (Diet+Rumen) rumen digestibility when TMR sieved material was reported on an as-fed (AF) or DM basis ${ }^{1}$

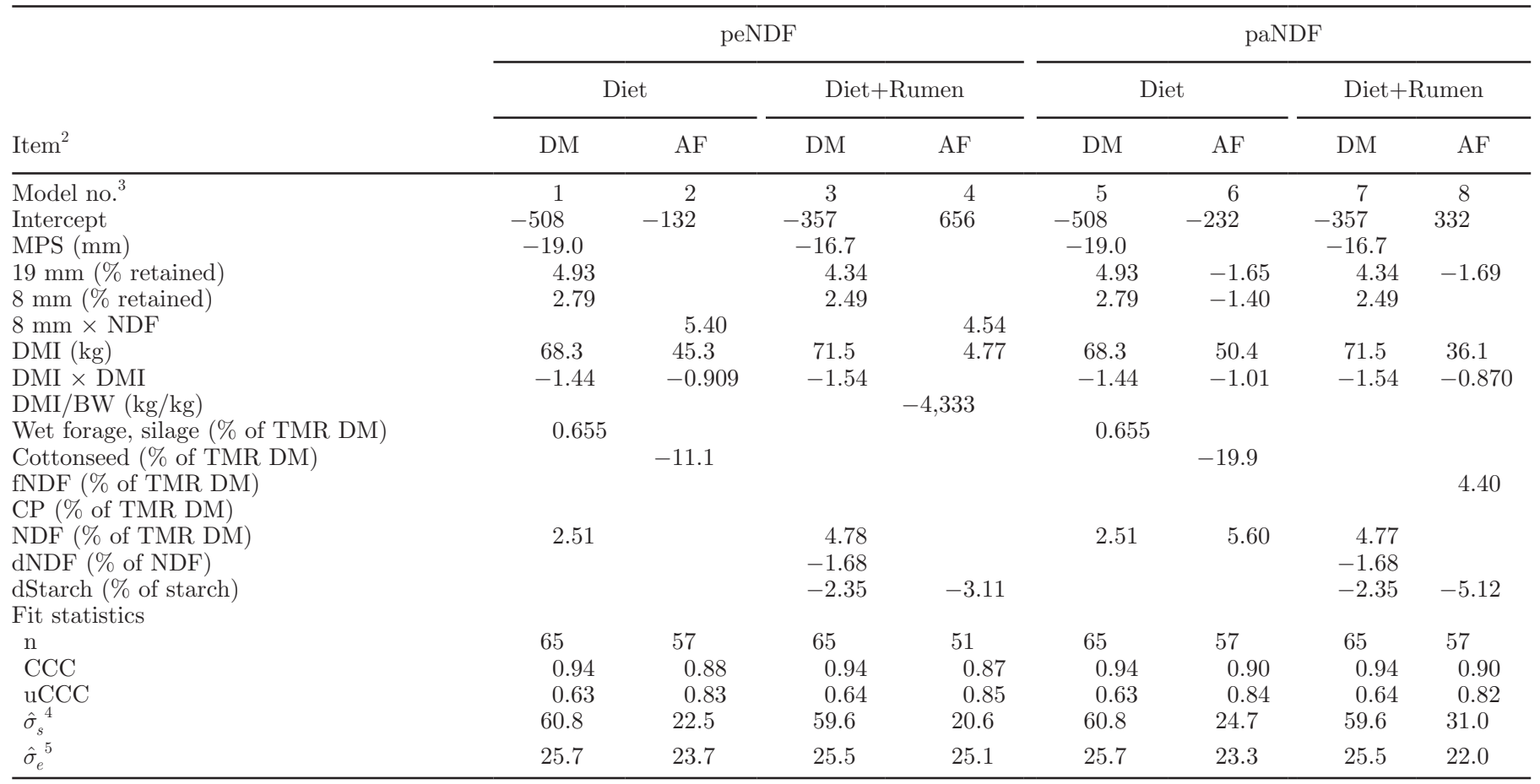

${ }^{1}$ Particle size was measured on the TMR by the Penn State Particle Separator (Heinrichs and Kononoff, 2002) and reported as percentage of TMR retained on the 19-, 8-, and 19+8- $\mathrm{mm}(>8 \mathrm{~mm})$ sieves on a DM basis or an AF basis.

${ }^{2}$ All coefficients are $P \leq 0.05$. Units of individual terms in interactions are the same as for the single terms. MPS $=$ mean particle size estimated when material retained in each sieve of the Penn State Particle Separator was reported on either a DM basis or an AF basis; fNDF = forage NDF; dNDF = rumen-degraded NDF as estimated by White et al. (2016); dStarch = rumen-degraded starch as estimated by White et al. (2016); $\mathrm{CCC}=$ concordance correlation coefficient; $\mathrm{uCCC}=$ unadjusted $\mathrm{CCC}$.

${ }^{3}$ Model number refers to those listed in Figure 1 and Table 4.

${ }^{4}$ Square root of the estimated variance associated with study.

${ }^{5}$ Square root of the estimated variance associated with residual error.

of total chewing time varied substantially in terms of the number of observations used in derivation, making some comparisons across models difficult. The model set for comparing DM and AF particle distributions within paNDF representations and including rumen factors had the closest number of observation used (Equation 3, $\mathrm{n}=65$; Equation 4, $\mathrm{n}=52$; Table 8). There was a moderate advantage when particle size data were expressed on an $\mathrm{AF}$ basis (uCCC Equation $4=0.74$ vs. Equation $3=0.68$; Table 8 ) to predict total chewing time. However, minimal uCCC differences were observed between all other model pairs even though the AF particle distribution models came from derivation data sets with larger numbers of observations than the DM particle distribution models. Only the AF-based model with peNDF representations resulted in significant coefficients for dNDF and dStarch. This was somewhat unexpected because of the consistent effects of these rumen terms on rumination time. The rumen-based relationships identified in the rumination time models appear to be diluted when rumination time was aggregated with eating time as total chewing time. The paNDF representations did not substantially affect model fit statistics (uCCC Equation $2=0.66$ to Equation $4=0.74$ vs. Equation $8=0.65$ to Equation $5,7=0.69$; Table 8 ). The MPS $\times$ dietary NDF term was the only peNDF metric that significantly affected total chewing time.

Prediction of Ruminal $\boldsymbol{p H}$. Ruminal $\mathrm{pH}$ is known as a key physicochemical measure of rumen fermentation (Aschenbach et al., 2011; Penner et al., 2011). If it is too low, it can influence the microbial community in the rumen and inhibit degradation of fiber (KrajcarskiHunt et al., 2002) and the flow of microbial CP out of the rumen (Firkins, 1996, 2010; Russell and Wilson, 1996). Nutritional factors known to reduce ruminal $\mathrm{pH}$ include the consumption of rapidly fermentable carbohydrates, most commonly starch (Firkins, 1996). The consumption of starch leads to the increased production of VFA, which in turn dissociate and decrease $\mathrm{pH}$. The 
Table 8. Parameter estimates in models of total chewing time when TMR particle size measure was (physically effective NDF; peNDF) or was not (physically adjusted NDF; paNDF) multiplied by diet NDF and including diet variables without (Diet) or with (Diet+Rumen) rumen digestibility when TMR sieved material was reported on an as-fed (AF) or DM basis ${ }^{1}$

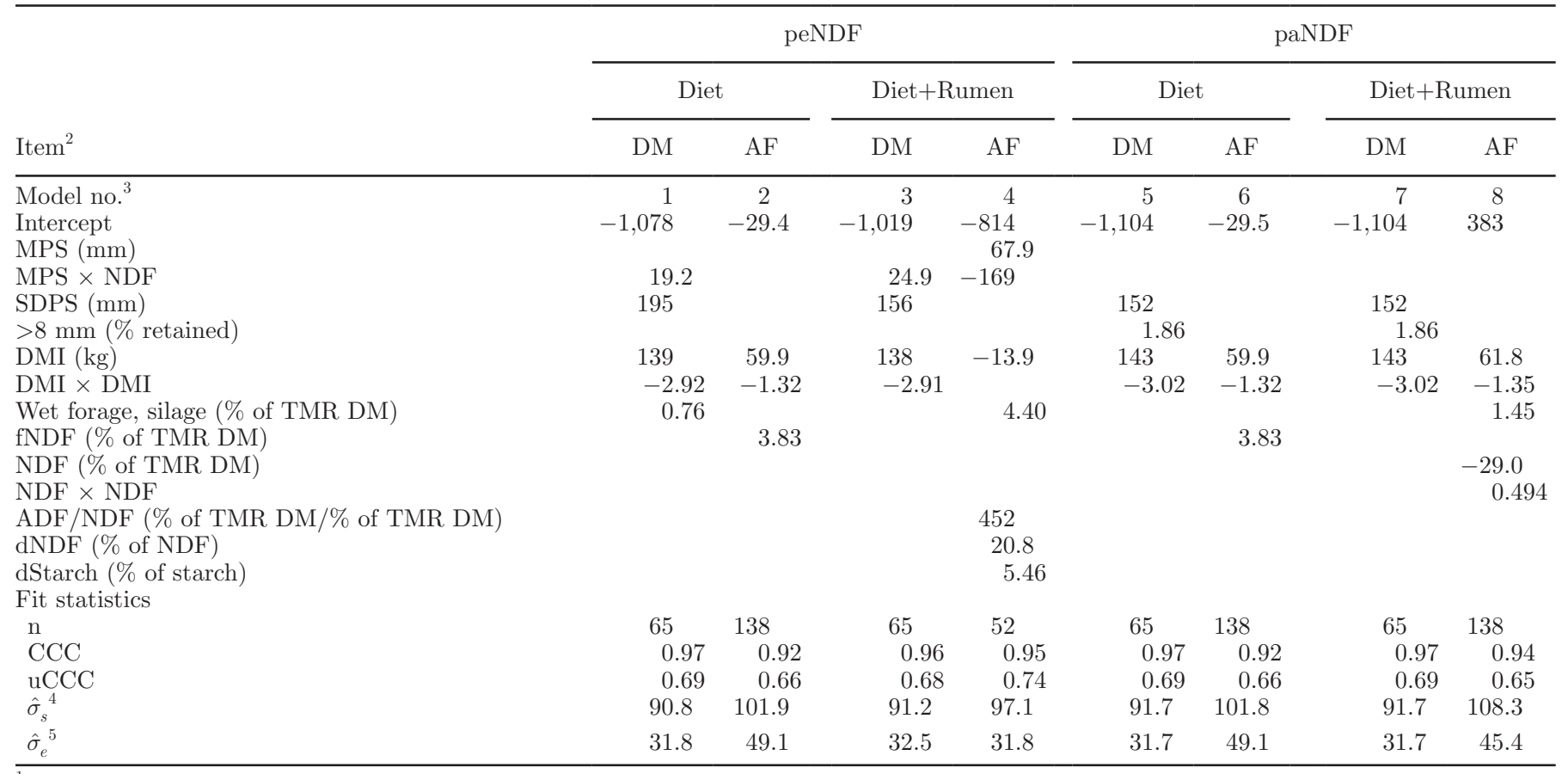

${ }^{1}$ Particle size was measured on the TMR by the Penn State Particle Separator (Heinrichs and Kononoff, 2002) and reported as percentage of TMR retained on the 19-, 8-, and 19+8-mm (>8 mm) sieves on a DM basis or an AF basis.

${ }^{2}$ All coefficients are $P \leq 0.05$. Units of individual terms in interactions are the same as for the single terms. MPS $=$ mean particle size estimated when material retained in each sieve of the Penn State Particle Separator was reported on either a DM basis or an AF basis; SDPS = standard deviation of the mean particle size; fNDF = forage NDF; dNDF = rumen-degraded NDF as estimated by White et al. (2016); dStarch = rumendegraded starch as estimated by White et al. (2016); CCC = concordance correlation coefficient; uCCC = unadjusted CCC.

${ }^{3}$ Model number refers to those listed in Figure 1 and Table 4.

${ }^{4}$ Square root of the estimated variance associated with study.

${ }^{5}$ Square root of the estimated variance associated with residual error.

effect of these protons on $\mathrm{pH}$ may be reduced through absorption of undissociated VFA, neutralization, and passage (NASEM, 2016). Ruminal $\mathrm{pH}$ is also believed to be maintained through the high buffering capacity of saliva, which contains bicarbonate, and phosphate buffers that neutralize protons produced in the rumen. Additional factors that are responsible for attenuating the effect of protons in the rumen include ammonia and particulate and liquid passage out of the rumen (Van Soest, 1994; Allen, 1997).

Comparison among models with particle size data expressed on an AF or DM basis (Table 9) is difficult because of the vast differences in the number of data points used to derive these models. Consequently, comparisons will be restricted within $\mathrm{DM}$ or AF factors; comparison across these factors is discussed in a companion paper (White et al., 2017a). In general, models with peNDF representations did not differ substantially from models with individual factor paNDF system representations, as indicated by similar uCCC (Equation 3
$=0.80$ vs. Equation $7=0.80$; Table 9 ) and $\hat{\sigma}_{e}$ (Equation $3=0.07$ vs. Equation $7=0.07$; Table 9$)$. Despite failing to dramatically improve model fit, the peNDF representations for MPS $\times \mathrm{NDF}$ and $>8 \mathrm{~mm} \times \mathrm{NDF}$ were significant in models 1 and 3 , respectively. The significance of these factors suggests that such an index does account for some variation in ruminal $\mathrm{pH}$. However, based on the current data, advantages of any peNDF index are not immediately apparent. Given the multitude of both animal and dietary factors that affect ruminal $\mathrm{pH}$, the peNDF index has been suggested to be an oversimplification (Plaizier et al., 2008) of a complex phenomenon and may be a more accurate index of chewing activity per se. Models that included rumen factors were also not substantially different in terms of fit (uCCC Equation $2=0.59$ vs. Equation $4=0.56$; Equation $5=0.79$ vs. Equation $7=0.80$; Table 9) when comparisons were restricted to those models with similar numbers of treatments used in derivation. In several models, dNDF and dStarch were significantly 
associated with ruminal $\mathrm{pH}$. Increased degradation of carbohydrates and resulting fermentation in the rumen is an obvious contributor to reduction in $\mathrm{pH}$ (Krause and Oetzel, 2006). Caution should be exercised when interpreting our observations of dNDF and dStarch in a mechanistic manner because these 2 factors tend to be inversely correlated (White et al., 2016).

Although total chewing time, eating time, ruminating time, and these factors divided by DMI were included in all initial $\mathrm{pH}$ models, only rumination time per unit of DMI was significant in the models (Equations 2, 4, 6, and 8; Table 9) that included AF representations of particle size. That rumination, but not eating activity, affects $\mathrm{pH}$ as observed experimentally (Beauchemin et al., 2003) might be because cows spend more total time ruminating compared with eating $(436 \pm 68.5$ and 284 $\pm 77.3 \mathrm{~min} / \mathrm{d}$, respectively; averages from the current data set). Given that the volume of saliva produced increases with DMI, albeit at a decreasing rate (Putnam et al., 1966), rumination time logically should be related mechanistically to DMI in an effective fiber system (Mertens, 1997).

To summarize, we originally hypothesized that particle size can be separated from the peNDF calculation and should be considered separately along with other dietary composition factors. The results of our study support this approach because when predicting rumen conditions, no apparent improvements were observed when including a representation of peNDF. By accounting for particle size separately, no assumption

Table 9. Parameter estimates in models of ruminal $\mathrm{pH}$ when TMR particle size measure was (physically effective NDF; peNDF) or was not (physically adjusted NDF; paNDF) multiplied by diet NDF and including diet variables without (Diet) or with (Diet+Rumen) rumen digestibility when TMR sieved material was reported on an as-fed (AF) or DM basis ${ }^{1}$

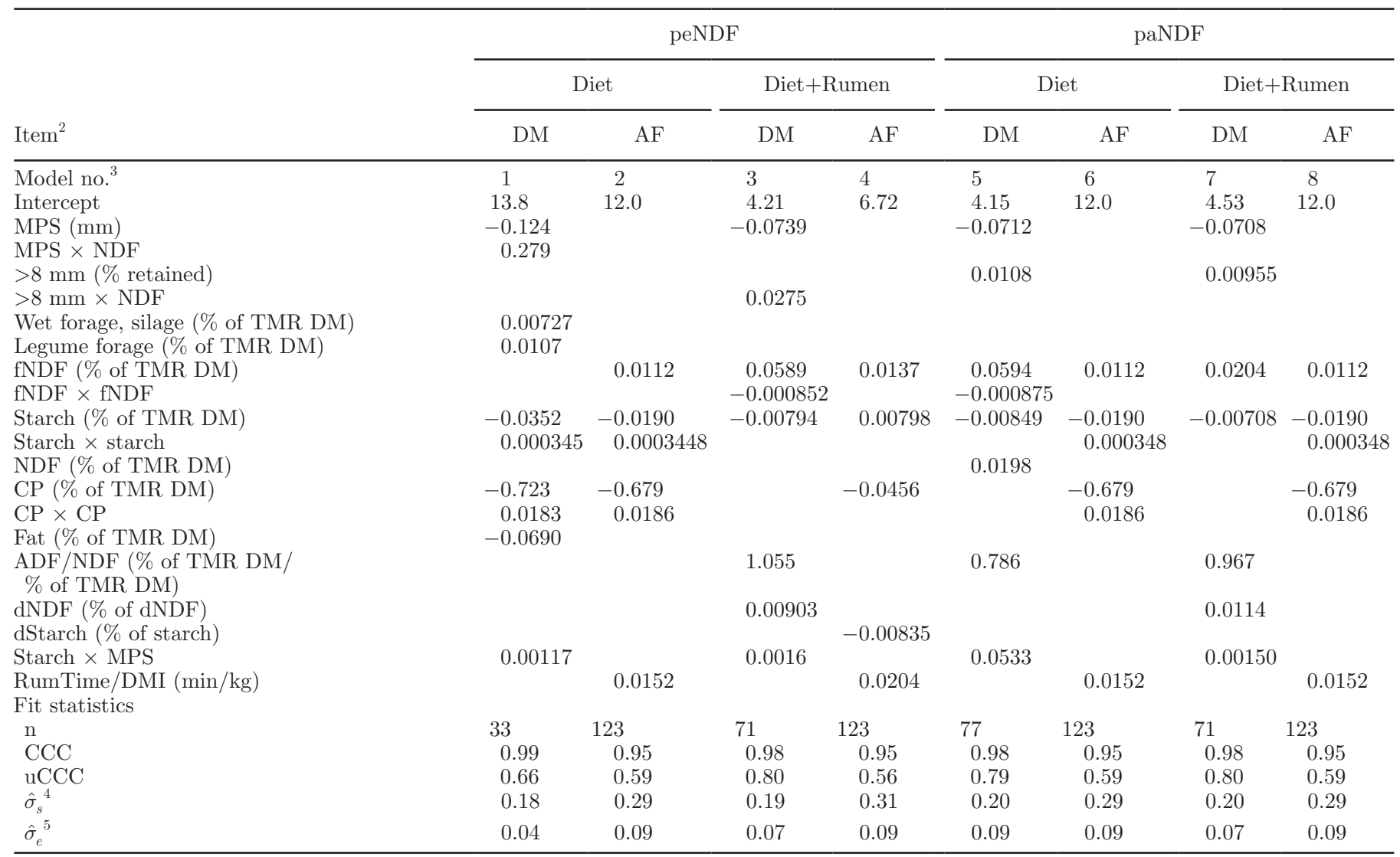

${ }^{1}$ Particle size was measured on the TMR by the Penn State Particle Separator (Heinrichs and Kononoff, 2002) and reported as percentage of TMR retained on the 19-, 8-, and 19+8- $\mathrm{mm}(>8 \mathrm{~mm})$ sieves on a DM basis or an AF basis.

${ }^{2}$ All coefficients are $P \leq 0.05$. Units of individual terms in interactions are the same as for the single terms. MPS $=$ mean particle size estimated when material retained in each sieve of the Penn State Particle Separator was reported on either a DM basis or an AF basis; fNDF $=$ forage NDF; dNDF = rumen-degraded NDF as estimated by White et al. (2016); dStarch = rumen-degraded starch as estimated by White et al. (2016); RumTime/DMI = time ruminating $(\mathrm{min} / \mathrm{d})$ divided by DMI $(\mathrm{kg} / \mathrm{d}) ; \mathrm{CCC}=$ concordance correlation coefficient; $\mathrm{uCCC}=\mathrm{unadjusted}$ CCC.

${ }^{3}$ Model number refers to those listed in Figure 1 and Table 4.

${ }^{4}$ Square root of the estimated variance associated with study.

${ }^{5}$ Square root of the estimated variance associated with residual error. 
is required regarding the relationship between NDF in each sieve fraction and that of the overall diet. We also hypothesized that dietary factors will improve accuracy and precision of predictions if total chewing is separated into eating and ruminating components. This was substantiated when also including dietary factors for predicting rumen conditions; rumination time but not eating time was observed to be an effector of rumen $\mathrm{pH}$. In addition, we hypothesized that chewing components will be better integrated if particle data are calculated on a DM. Because of the large differences in data availability for $\mathrm{DM}$ versus $\mathrm{AF}$ model evaluation, it is not feasible to make a definitive conclusion about the adequacy of DM versus AF descriptions of particle size data from the analysis presented in this work. Further work objectively comparing these reporting standards on equivalent databases is presented in White et al. (2017b) and was necessary to evaluate this hypothesis. Finally, we hypothesized that incorporating predicted rumen NDF or starch degradability estimates into models (Roman-Garcia et al., 2016) will improve fit compared with diet-only factors. In the equations, rumen degradation of NDF or starch was frequently observed to be a significant effector of DMI, rumination time, and ultimately rumen conditions. This observation on the effect of digestibility further supports the idea that an effective fiber index not including these factors is overly simplistic.

\section{CONCLUSIONS}

In this study, we evaluated both technical aspects of estimating peNDF and the effects of these representations on responses in studies with lactating dairy cattle. Model differences were observed when representing particle size data on an AF or DM basis. Ruminating time is affected by both chemical and physical characteristics of the TMR, and integration of dNDF and starch improved prediction of this activity. As expected, a large number of dietary chemical and physical factors were identified as influencing mean ruminal $\mathrm{pH}$. In several cases, prediction was improved when also accounting for rumination times and dNDF or dStarch. These results were assumed to justify the development of a modeling approach to integrate physical and chemical factors to predict effects on ruminal $\mathrm{pH}$ in a companion paper.

\section{ACKNOWLEDGMENTS}

The authors thank Keri Rogan and Jared Judy for their efforts related to data entry. Funding for this project was provided by Agriculture and Food Research Initiative Competitive grant no. 2015-03656 from the
USDA National Institute of Food and Agriculture (Washington, DC). Research was supported by state and federal funds appropriated to the University of Nebraska-Lincoln, Virginia Tech (Blacksburg), and The Ohio State University (Columbus) with funding from USDA Agricultural Research Service (Washington, DC).

\section{REFERENCES}

Akinwande, M. O., H. G. Dikko, and A. Samson. 2015. Variance inflation factor: As a condition for the inclusion of suppressor variable(s) in regression analysis. Open J. Stat. 5:754-767.

Albright, J. L. 1993. Feeding behavior of dairy cattle. J. Dairy Sci. 76:485-498. https://doi.org/10.3168/jds.S0022-0302(93)77369-5.

Albright, J. L., and C. W. Arave. 1997. The Behaviour of Cattle. CAB International, Wallingford, United Kingdom.

Allen, M. S. 1997. Relationship between fermentation acid production in the rumen and the requirement for physically effective fiber. J. Dairy Sci. 80:1447-1462. https://doi.org/10.3168/jds.S0022 -0302(97)76074-0.

Allen, M. S., and D. R. Mertens. 1988. Evaluating constraints on fiber digestion by rumen microbes. J. Nutr. 118:261-270.

Armentano, L., and M. Pereira. 1997. Measuring the effectiveness of fiber by animal response trials. J. Dairy Sci. 80:1416-1425.

ASABE. 2013. Method of determining and expressing fineness of feed materials by sieving. ANSI/ASAE S319.4. Approved February 2008: Reaffirmed February 2013.

ASABE. 2017. Method of of determining and expressing particle size of chopped forage materials by screening, ANSI/ASAE S424.1. ANSI/ASAE S424.1 Revision Approved September 1992; Reaffirmed January 2017.

Aschenbach, J. R., G. B. Penner, F. Stumpff, and G. Gabel. 2011. Role of fermentation acid absorption in the regulation of ruminal $\mathrm{pH}$. J. Anim. Sci. 89:1092-1107. https://doi.org/10.2527/jas.2010-3301.

Balch, C. C. 1971. Proposal to use time spent chewing as an index of the extent to which diets for ruminants possess the physical property of fibrousness characteristic of roughages. Br. J. Nutr. $26: 383-392$.

Beauchemin, K. A. 1991. Ingestion and mastication of feed by dairy cattle. Vet. Clin. North Am. Food Anim. Pract. 7:439-463. https:// doi.org/10.1016/S0749-0720(15)30794-5.

Beauchemin, K. A., L. Eriksen, P. Nørgaard, and L. M. Rode. 2008. Short communication: Salivary secretion during meals in lactating dairy cattle. J. Dairy Sci. 91:2077-2081. https://doi.org/10.3168/ jds.2007-0726.

Beauchemin, K. A., L. M. Rode, and M. V. Eliason. 1997. Chewing activities and milk production of dairy cows fed alfalfa as hay, silage, or dried cubes of hay or silage. J. Dairy Sci. 80:324-333. https:// doi.org/10.3168/jds.S0022-0302(97)75942-3.

Beauchemin, K. A., W. Z. Yang, and L. M. Rode. 2003. Effects of particle size of alfalfa-based dairy cow diets on chewing activity, ruminal fermentation, and milk production. J. Dairy Sci. 86:630-643.

Bibby, J., and H. Toutenburg. 1978. Improved estimation and prediction. Z. Angew. Math. Mech. 58:45-49. https://doi.org/10.1002/ zamm.19780580108.

Boerman, J. P., J. L. Firkins, N. R. St-Pierre, and A. L. Lock. 2015. Intestinal digestibility of long-chain fatty acids in lactating dairy cows: A meta-analysis and meta-regression. J. Dairy Sci. 98:8889 8903

Bradford, B. J., and C. R. Mullins. 2012. Invited review: Strategies for promoting productivity and health of dairy cattle by feeding nonforage fiber sources. J. Dairy Sci. 95:4735-4746. https://doi .org/10.3168/jds.2012-5393.

Calberry, J. M., J. C. Plaizier, M. S. Einarson, and B. W. McBride. 2003. Effects of replacing chopped alfalfa hay with alfalfa silage in a total mixed ration on production and rumen conditions of lactating dairy cows. J. Dairy Sci. 86:3611-3619. 
Cardoza, R. S. 1985. Threshold size and factors affecting fecal particle weight distribution. MS Thesis. Univ. of Georgia, Athens.

Cole, H. H., and S. W. Mead. 1943. A physical deficiency in the ration of ruminants. Science 98:543-544. https://doi.org/10.1126/science .98.2555.543.

Devries, T. J., F. Dohme, and K. A. Beauchemin. 2008. Repeated ruminal acidosis challenges in lactating dairy cows at high and low risk for developing acidosis: Feed sorting. J. Dairy Sci. 91:39583967. https://doi.org/10.3168/jds.2008-1347.

Firkins, J. L. 1996. Maximizing microbial protein synthesis in the rumen. J. Nutr. 126:1347S-1354S.

Firkins, J. L. 1997. Effects of feeding nonforage fiber sources on site of fiber digestion. J. Dairy Sci. 80:1426-1437.

Firkins, J. L. 2010. Reconsidering rumen microbial consortia to enhance feed efficiency and reduce environmental impact of ruminant livestock production systems. Rev. Bras. Zootec. 39:445-457.

Grant, R. 2010. Forage fragility, fiber digestibility, and chewing response in dairy cattle. Pages 27-40 in Proc. Tri-State Dairy Nutrition Conference. The Ohio State University, Columbus.

Grant, R. J. 1997. Interactions among forages and nonforage fiber sources. J. Dairy Sci. 80:1438-1446.

Grant, R. J., K. W. Cotanch, and N. Y. Chazy. 2005. Physically effective fiber for dairy cows: Current perspectives. Pages 18-20 in Proc. Cornell Nutr. Conf. for Feed Manufacturers. Cornell University, Ithaca, NY.

Heinrichs, A. J., D. R. Buckmaster, and B. P. Lammers. 1999. Processing, mixing, and particle size reduction of forages for dairy cattle. J. Anim. Sci. 77:180-186.

Heinrichs, J., and P. Kononoff. 2002. Evaluating particle size of forages and TMRs using the new Penn State Forage Particle Separator. Pa. State Univ. Coll. Agric. Sci. Coop. Ext. DAS 02-42. Pennsylvania State University, University Park.

Hofmann, R. R. 1989. Evolutionary steps of ecophysiological adaptation and diversification of ruminants: A comparative view of their digestive system. Oecologia 78:443-457. https://doi.org/10.1007/ BF00378733.

Holter, J. B., J. W. West, and M. L. McGilliard. 1997. Predicting ad libitum dry matter intake and yield of Holstein cows. J. Dairy Sci. 80:2188-2199. https://doi.org/10.3168/jds.S0022-0302(97)76167 -8 .

Hurvich, C. M., and C.-L. Tsai. 1993. A corrected Akaike information criterion for vector autoregressive model selection. J. Time Ser. Anal. 14:271-279. https://doi.org/10.1111/j.1467-9892.1993 .tb00144.x.

Jaster, E. H., and M. R. Murphy. 1983. Effects of varying particle size of forage on digestion and chewing behavior of dairy heifers. J. Dairy Sci. 66:802-810. https://doi.org/10.3168/jds.S0022 $-0302(83) 81860-8$.

Jensen, L. M., B. Markussen, N. I. Nielsen, E. Nadeau, M. R. Weisbjerg, and P. Nørgaard. 2016. Description and evaluation of a net energy intake model as a function of dietary chewing index. J. Dairy Sci. 99:8699-8715. https://doi.org/10.3168/jds.2015-10389.

Kmicikewycz, A. D., K. J. Harvatine, and A. J. Heinrichs. 2015. Effects of corn silage particle size, supplemental hay, and forageto-concentrate ratio on rumen $\mathrm{pH}$, feed preference, and milk fat profile of dairy cattle. J. Dairy Sci. 98:4850-4868. https://doi.org/ 10.3168/jds.2014-9249.

Kmicikewycz, A. D., and A. J. Heinrichs. 2015. Effect of corn silage particle size and supplemental hay on rumen $\mathrm{pH}$ and feed preference by dairy cows fed high-starch diets. J. Dairy Sci. 98:373-385. https://doi.org/10.3168/jds.2014-8103.

Kononoff, P. J., A. J. Heinrichs, and D. R. Buckmaster. 2003. Modification of the Penn State forage and total mixed ration particle separator and the effects of moisture content on its measurements. J. Dairy Sci. 86:1858-1863.

Krajcarski-Hunt, H., J. C. Plaizier, J.-P. Walton, R. Spratt, and B. W. McBride. 2002. Short communication: Effect of subacute ruminal acidosis on in situ fiber digestion in lactating dairy cows. J. Dairy Sci. 85:570-573. https://doi.org/10.3168/jds.S0022-0302(02)74110 -6 .
Krause, K. M., and G. R. Oetzel. 2006. Understanding and preventing subacute ruminal acidosis in dairy herds: A review. Anim. Feed Sci. Technol. 126:215-236. https://doi.org/10.1016/j.anifeedsci 2005.08.004.

Kuznetsova, A., P. B. Brockhoff, and R. H. B. Christensen. 2015. lmerTest: Tests in Linear Mixed Effects Models: Version 2.0-29. Accessed May 1, 2016. https://cran.r-project.org/web/packages/ lmerTest/index.

Lammers, B. P., D. R. Buckmaster, and A. J. Heinrichs. 1996. A simple method for the analysis of particle sizes of forage and total mixed rations. J. Dairy Sci. 79:922-928. https://doi.org/10.3168/ jds.S0022-0302(96)76442-1.

Leonardi, C. K. J. Shinners, and L. E. Armentano. 2005. Effect of different dietary geometric mean particle length and particle size distribution of oat silage on feeding behavior and productive performance of dairy cattle. J. Dairy Sci. 88:698-710.

Lin, L. I. 1989. A concordance correlation coefficient to evaluate reproducibility. Biometrics 45:255-268

Maekawa, M., K. A. Beauchemin, and D. A. Christensen. 2002a. Chewing activity, saliva production, and ruminal $\mathrm{pH}$ of primiparous and multiparous lactating dairy cows. J. Dairy Sci. 85:1176-1182. https://doi.org/10.3168/jds.S0022-0302(02)74180-5.

Maekawa, M., K. A. Beauchemin, and D. A. Christensen. 2002b. Effect of concentrate level and feeding management on chewing activities, saliva production, and ruminal $\mathrm{pH}$ of lactating dairy cows. J. Dairy Sci. 85:1165-1175. https://doi.org/10.3168/jds.S0022 -0302(02)74179-9.

Maulfair, D. D., M. Fustini, and A. J. Heinrichs. 2011. Effect of varying total mixed ration particle size on rumen digesta and fecal particle size and digestibility in lactating dairy cows. J. Dairy Sci. 94:3527-3536. https://doi.org/10.3168/jds.2010-3718.

Maulfair, D. D., and A. J. Heinrichs. 2012. Methods to measure forage and diet particle size in the dairy cow. Prof. Anim. Sci. 28:489-493.

Maulfair, D. D., G. I. Zanton, M. Fustini, and A. J. Heinrichs. 2010. Effect of feed sorting on chewing behavior, production, and rumen fermentation in lactating dairy cows. J. Dairy Sci. 93:4791-4803. https://doi.org/10.3168/jds.2010-3278.

Mayer, D. G., J. A. Belward, and K. Burrage. 1998. Optimizing simulation models of agricultural systems. Ann. Oper. Res. 82:219-232.

Mertens, D. R. 1997. Creating a system for meeting the fiber requirements of dairy cows. J. Dairy Sci. 80:1463-1481. https://doi.org/ 10.3168/jds.S0022-0302(97)76075-2.

Murphy, M. R., and J. S. Zhu. 1997. A comparison of methods to analyze particle size as applied to alfalfa haylage, corn silage, and concentrate mix. J. Dairy Sci. 80:2932-2938. https://doi.org/10 .3168/jds.S0022-0302(97)76259-3.

Nasrollahi, S. M., M. Imani, and Q. Zebeli. 2015. A meta-analysis and meta-regression of the effect of forage particle size, level, source, and preservation method on feed intake, nutrient digestibility, and performance in dairy cows. J. Dairy Sci. 98:8926-8939. https://doi .org/10.3168/jds.2015-9681.

Nasrollahi, S. M., M. Imani, and Q. Zebeli. 2016. A meta-analysis and meta-regression of the impact of particle size, level, source and preservation method of forages on chewing behavior and ruminal fermentation in dairy cows. Anim. Feed Sci. Technol. 219:144-158. https://doi.org/10.1016/j.anifeedsci.2016.06.012.

NASEM (National Academies of Sciences, Engineering, and Medicine). 2016. Nutrient Requirements of Beef Cattle. 8th rev. ed. Natl. Acad. Press, Washington, DC.

Nørgaard, P. 1989. The influence of physical form of ration on chewing activity and rumen motility in lactating cows. Acta Agric. Scand. 39:187-202. https://doi.org/10.1080/00015128909438512.

Nørgaard, P. 2006. Use of image analysis for measuring particle size in feed, digesta and faeces. Pages 579-585 in Ruminant Physiology: Digestion, Metabolism and Impact of Nutrition on Gene Expression, Immunology and Stress. K. Sejrsen, T. Hvelplund, and M. O. Nielsen, ed. Wageningen Academic Publishers, Wageningen, the Netherlands.

Nousiainen, J., M. Rinne, and P. Huhtanen. 2009. A meta-analysis of feed digestion in dairy cows. 1 . The effects of forage and concen- 
trate factors on total diet digestibility. J. Dairy Sci. 92:5019-5030. https://doi.org/10.3168/jds.2008-1833.

NRC. 2001. Nutrient Requirements of Dairy Cattle. 7th rev. ed. Natl. Acad. Sci., Washington, DC.

Oba, M., and M. S. Allen. 1999. Evaluation of the importance of the digestibility of neutral detergent fiber from forage: Effects on dry matter intake and milk yield of dairy cows. J. Dairy Sci. 82:589 596. https://doi.org/10.3168/jds.S0022-0302(99)75271-9.

Offner, A., and D. Sauvant. 2004. Prediction of in vivo starch digestion in cattle from in situ data. Anim. Feed Sci. Technol. 111:41-56. https://doi.org/10.1016/S0377-8401(03)00216-5.

Penner, G. B., M. A. Steele, J. R. Aschenbach, and B. W. McBride. 2011. Molecular adaptation of ruminal epithelia to highly fermentable diets. J. Anim. Sci. 89:1108-1119. https://doi.org/10.2527/ jas.2010-3378.

Plaizier, J. C., D. O. Krause, G. N. Gozho, and B. W. McBride. 2008. Subacute ruminal acidosis in dairy cows: The physiological causes, incidence and consequences. Vet. J. 176:21-31. https://doi.org/10 $.1016 / j . t v j 1.2007 .12 .016$.

Poppi, D. P., B. W. Norton, D. J. Minson, and R. E. Hendricksen. 1980. The validity of the critical size theory for particles leaving the rumen. J. Agric. Sci. 94:275-280. https://doi.org/10.1017/ S0021859600028859.

Putnam, P. A., R. Lehmann, and R. E. Davis. 1966. Feed intake and salivary secretion by steers. J. Anim. Sci. 25:817-820.

$\mathrm{R}$ Core Team. 2014. A language and environment for statistical computing. Version 3.1.0. R. Foundation for Statistical Computing, Vienna, Austria.

Ranathunga, S. D., K. F. Kalscheur, A. R. Hippen, and D. J. Schingoethe. 2010. Replacement of starch from corn with nonforage fiber from distillers grains and soyhulls in diets of lactating dairy cows. J. Dairy Sci. 93:1086-1097. https://doi.org/10.3168/jds.2009 -2332 .

Roman-Garcia, Y., R. R. White, and J. L. Firkins. 2016. Meta-analysis of postruminal microbial nitrogen flows in dairy cattle. I. Derivation of equations. J. Dairy Sci. 99:7918-7931. https://doi.org/10 $.3168 /$ jds.2015-10661.

Russell, J. B., and D. B. Wilson. 1996. Why are ruminal cellulolytic bacteria unable to digest cellulose at low $\mathrm{pH}$ ? J. Dairy Sci 79:1503-1509. https://doi.org/10.3168/jds.S0022-0302(96)76510 -4 .

Santini, F. J., A. R. Hardie, N. A. Jorgensen, and M. F. Finner. 1983. Proposed use of adjusted intake based on forage particle length for calculation of roughage indexes. J. Dairy Sci. 66:811-820. https:// doi.org/10.3168/jds.S0022-0302(83)81861-X.

Schadt, I., J. D. Ferguson, G. Azzaro, R. Petriglieri, M. Caccamo, P. Van Soest, and G. Licitra. 2012. How do dairy cows chew?-Particle size analysis of selected feeds with different particle length distributions and of respective ingested bolus particles. J. Dairy Sci. 95:4707-4720. https://doi.org/10.3168/jds.2011-5118.

Shaver, R. D., A. J. Nytes, L. D. Satter, and N. A. Jorgensen. 1988. Influence of feed intake, forage physical form, and forage fiber content on particle size of masticated forage, ruminal digesta, and feces of dairy cows. J. Dairy Sci. 71:1566-1572. https://doi.org/10 .3168/jds.S0022-0302(88)79720-9.

Sova, A. D., S. J. LeBlanc, B. W. McBride, and T. J. DeVries. 2014 Accuracy and precision of total mixed rations fed on commercial dairy farms. J. Dairy Sci. 97:562-571. https://doi.org/10.3168/jds .2013-6951.

Sudweeks, E. M., L. O. Ely, D. R. Mertens, and L. R. Sisk. 1981. Assessing minimum amounts and form of roughages in ruminant diets: Roughage value index system. J. Anim. Sci. 53:1406-1411.
Susenbeth, A., R. Mayer, B. Koehler, and O. Neumann. 1998. Energy requirement for eating in cattle. J. Anim. Sci. 76:2701-2705. https://doi.org/10.2527/1998.76102701x.

Vallimont, J. E., C. D. Dechow, J. M. Daubert, M. W. Dekleva, J W. Blum, C. M. Barlieb, W. Liu, G. A. Varga, A. J. Heinrichs, and C. R. Baumrucker. 2010. Genetic parameters of feed intake, production, body weight, body condition score, and selected type traits of Holstein cows in commercial tie-stall barns. J. Dairy Sci 93:4892-4901. https://doi.org/10.3168/jds.2010-3189.

Van Soest, P. J. 1994. Nutritional Ecology of the Ruminant. 2nd ed. Comstock, Ithaca, NY.

Waldo, D. R., L. W. Smith, E. L. Cox, B. T. Weinland, and H. L. Lucas. 1971. Logarithmic normal distribution for description of sieved forage materials. J. Dairy Sci. 54:1465-1469. https://doi .org/10.3168/jds.S0022-0302(71)86048-4.

Weiss, W. P., and D. J. Wyatt. 2000. Effect of oil content and kernel processing of corn silage on digestibility and milk production by dairy cows. J. Dairy Sci. 83:351-358. https://doi.org/10.3168/jds .S0022-0302(00)74886-7.

White, R. R., M. B. Hall, J. Firkins, and P. J. Kononoff. 2017a. Physically adjusted neutral detergent fiber system for lactating dairy cow rations. II: Development of feeding recommendations. J. Dairy Sci. 100:9569-9584. https://doi.org/10.3168/jds.2017-12766.

White, R. R., Y. Roman-Garcia, and J. L. Firkins. 2016. Meta-analysis of postruminal microbial nitrogen flows in dairy cattle. II. Approaches to and implications of more mechanistic prediction. J Dairy Sci. 99:7932-7944. https://doi.org/10.3168/jds.2015-10662.

White, R. R., Y. Roman-Garcia, J. L. Firkins, P. Kononoff, M. J. VandeHaar, H. Tran, T. McGill, R. Garnett, and M. D. Hanigan. 2017b. Evaluation of the National Research Council (2001) dairy model and derivation of new prediction equations. 2. Rumen degradable and undegradable protein. J. Dairy Sci. 100:3611-3627.

White, R. R., Y. Roman-Garcia, J. L. Firkins, M. J. VandeHaar, L. E. Armentano, W. P. Weiss, T. McGill, R. Garnett, and M. D. Hanigan. 2017c. Evaluation of the National Research Council (2001) dairy model and derivation of new prediction equations. 1. Digestibility of fiber, fat, protein, and nonfiber carbohydrate. J. Dairy Sci. 100:3591-3610.

Yang, Y. 2007. Image and sieve analysis of biomass particle sizes and separation after size reduction. MS Thesis. University of Tennessee, Knoxville.

Zebeli, Q., J. R. Aschenbach, M. Tafaj, J. Boguhn, B. N. Ametaj, and W. Drochner. 2012. Invited review: Role of physically effective fiber and estimation of dietary fiber adequacy in high-producing dairy cattle. J. Dairy Sci. 95:1041-1056. https://doi.org/10.3168/ jds.2011-4421

Zebeli, Q., J. Dijkstra, M. Tafaj, H. Steingass, B. N. Ametaj, and W. Drochner. 2008a. Modeling the adequacy of dietary fiber in dairy cows based on the responses of ruminal $\mathrm{pH}$ and milk fat production to composition of the diet. J. Dairy Sci. 91:2046-2066. https://doi.org/10.3168/jds.2007-0572.

Zebeli, Q.. D. Mansmann, B. N. Ametaj. H. Steingaß, and W. Drochner. 2010. A model to optimise the requirements of lactating dairy cows for physically effective neutral detergent fibre. Arch. Anim. Nutr. 64:265-278. https://doi.org/10.1080/1745039X.2010.486603.

Zebeli, Q., M. Tafaj, B. Junck, V. Olschläger, B. N. Ametaj, and W. Drochner. 2008b. Evaluation of the response of ruminal fermentation and activities of nonstarch polysaccharide-degrading enzymes to particle length of corn silage in dairy cows. J. Dairy Sci 91:2388-2398. https://doi.org/10.3168/jds.2007-0810. 